\title{
Integration of Unmanned Aircraft Systems into the National Airspace System-Efforts by the University of Alaska to Support the FAA/NASA UAS Traffic Management Program
}

\author{
Michael Hatfield ${ }^{1, *}$, Catherine Cahill ${ }^{2}\left(\mathbb{0}\right.$, Peter Webley ${ }^{2}$, Jessica Garron ${ }^{2}$ and Rebecca Beltran ${ }^{3}$ \\ College of Engineering and Mines, University of Alaska Fairbanks, AK 99775, USA \\ 2 Geophysical Institute/Alaska Center for Unmanned Aircraft Systems Integration, University of Alaska \\ Fairbanks, AK 99775, USA; cfcahill@alaska.edu (C.C.); pwwebley@alaska.edu (P.W.); \\ jigarron@alaska.edu (J.G.) \\ 3 School of Management, University of Alaska Fairbanks, AK 99775, USA; rabeltran@alaska.edu \\ * Correspondence: mchatfield@alaska.edu
}

Received: 31 July 2020; Accepted: 10 September 2020; Published: 23 September 2020

\begin{abstract}
Over the past decade Unmanned Aircraft Systems (UAS, aka "drones") have become pervasive, touching virtually all aspects of our world. While UAS offer great opportunity to better our lives and strengthen economies, at the same time these can significantly disrupt manned flight operations and put our very lives in peril. Balancing the demanding and competing requirements of safely integrating UAS into the United States (US) National Airspace System (NAS) has been a top priority of the Federal Aviation Administration (FAA) for several years. This paper outlines efforts taken by the FAA and the National Aeronautics and Space Administration (NASA) to create the UAS Traffic Management (UTM) system as a means to address this capability gap. It highlights the perspectives and experiences gained by the University of Alaska Fairbanks (UAF) Alaska Center for Unmanned Aircraft Systems Integration (ACUASI) as one of the FAA's six UAS test sites participating in the NASA-led UTM program. The paper summarizes UAF's participation in the UTM Technical Capability Level (TCL1-3) campaigns, including flight results, technical capabilities achieved, lessons learned, and continuing challenges regarding the implementation of UTM in the NAS. It also details future efforts needed to enable practical Beyond-Visual-Line-of-Sight (BVLOS) flights for UAS operations in rural Alaska.
\end{abstract}

Keywords: UAS; drone; UTM; remote sensing

\section{Introduction}

This paper describes efforts by the University of Alaska Fairbanks (UAF) under the Federal Aviation Administration (FAA)/NASA Unmanned Aircraft Systems (UAS) Traffic Management (UTM) program to safely integrate UAS into the US National Airspace System (NAS). It details the flight campaigns of UAF's Alaska Center for Unmanned Aircraft Systems Integration (ACUASI), an FAA UAS Test Site, in supporting the program goals and objectives. The paper outlines UAF's flight campaign activities, demonstration results, and continuing efforts in support of the UTM program and long-term Beyond Visual Line-Of-Sight (BVLOS) operations necessary for conduct of arctic research and public service missions in Alaska.

The remainder of this section examines the popularity of UAS, some economic drivers behind this trend, and the need to smartly regulate the integration of UAS activities within the NAS. Section 2, Materials and Methods, details UAF's participation in the UTM program through Technical Capability 
Level (TCL) phases 1-3. Section 3, Discussion, highlights results of the flight campaigns, technical achievements, and lessons learned. Section 4, Conclusions, outlines ongoing efforts and future work needed to advance UAF's BVLOS capabilities in the remote Alaskan environment. The Appendix A includes a comprehensive list of acronyms, excerpts from the NASA Statements of Work (SoW), and list of references.

Background: The US and the world have seen a dramatic rise in popularity and application of Unmanned Aircraft Systems (UAS) in recent years. UAS of many sizes, shapes, and characteristics are being flown in unprecedented numbers and applications today. Like many other technological advances that consumers interact with on a daily basis, UAS, aka Unmanned Aerial Vehicles (UAV), or "drones", applications are expanding daily. UAS initially were expensive and of limited utility to the general public, but recent technological improvements and market forces as shown in Figure 1A, have resulted in a virtual explosion in the availability of complex and affordable UAS capable of satisfying a wide spectrum of mission sets and operating requirements [1] (p. 5).

A 2020 survey of over 1000 participants showed that $15 \%$ of Americans have flown a drone, and $8 \%$ own at least one [2] (pp. 1-3). This shows the increasing interest in UAS by hobbyists, but the need for UAS technology is increasingly being noticed by the commercial sector as well. UAS are now applicable to a multitude of sectors including media, real estate, disaster response, mining, maritime, education, construction, tourism, utilities, agriculture, meteorology, aviation, and logistics including the experimentation of home delivery by large logistical companies such as Amazon, UPS, and Google [3] (p. 2). This technology is now so highly in demand that the number of UAS over 55 pounds is expected to surpass the number of active GA (General Aviation) aircrafts in less than 15 years as seen in Figure 1B [4] (p. 8).
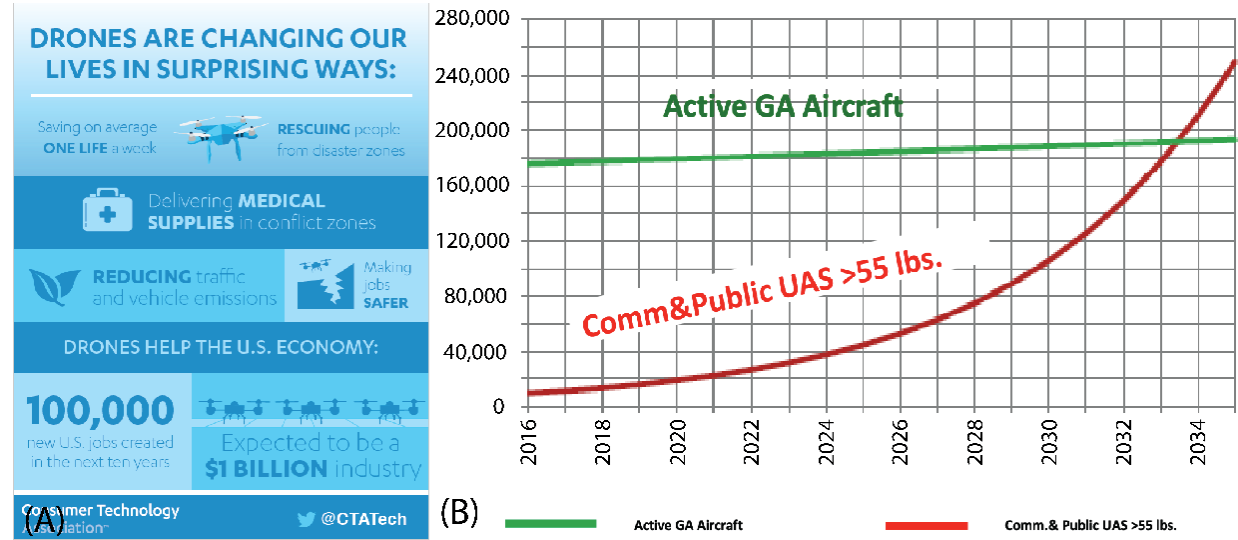

Figure 1. (A) Impact of the Unmanned Aircraft Systems (UAS) industry (C) 2018, CTA ${ }^{\mathrm{TM}}$ [5] (p. 4) and (B) Federal Aviation Administration (FAA) prediction of General Aviation (GA) UAS over 55 lbs. (C) 2018, CTA ${ }^{\mathrm{TM}}[4]$ (p. 8).

Integrating UAS into the NAS: Although technological advancements regarding UAS and their popularity are both on the rise [6] (p. 1), there are other barriers slowing UAS growth potential, including Federal Aviation Administration (FAA) regulations, public acceptance, and national/state infrastructure [7] (p. 2). One of the largest barriers in growing the UAS-based economy sector today is the need to responsibly and safely integrate UAS into the National Airspace System (NAS). While UAS have been in existence for over a century, integration of these aircraft for civilian purposes into the NAS has not yet been established, as the UAS flight is still too unique to completely adopt General Aviation's (GA's) current system. The need for regulations specifically governing the use of small UAS under $55 \mathrm{lbs}$. has been highly voiced, but at present does not match the technical capability and popularity of today's systems.

While there is universal recognition that safety is paramount in this effort, many criticize that the FAA has been overly cautious due to a lack of policy differentiating drones and their abilities. 
For example, current FAA policy treats a hobbyist drone the same as emergency services UAS [7] (p. 15). The balance between safety and growth has many stakeholders frustrated as technology leaps ahead, while the legal ability to utilize that technology lags behind. Every year that UAS integration into the NAS is unavailable, the US loses more than $\$ 10$ billion amounting to $\$ 27.6$ million per day of potential economic impact lost [8] (p. 2). In addition, stakeholders are calling for comprehensive legislature that would define responsibilities and liabilities in case of accidents so they may balance risk and reward and ensure that insurance and financial firms are able to support the UAS market because without safe protocols there will be no support for the market [9] (p. 3).

UAS flight regulations, the scope of the issue, and the potential consequences cannot be taken lightly. In 2012, there were an estimated 200,000 h of domestic UAS operations and that figure was predicted to be at over a million hours in 2020 [10] (p. 17). In 2016, the FAA started a registration system to understand how many UAS there are in the US. Within the first month of opening the registration site there were nearly 300,000 UAS owners that registered their vehicles [3] (p. 2). In 2018 more than 175,000 new commercial UAS were registered, increasing the number in the US by more than $170 \%$ and expanding the total commercial market to 277,000 units. This far exceeded the $44 \%$ of growth that had been expected for the year [11] (p. 1).

In the same report, the FAA predicted there would be around 452,000 commercial UAS in use by 2022, but that number was already reached by the beginning of March 2020 [12] (pp. 1 and 9). Based on the latest data the FAA now expects there to be 835,000 commercial UAS by 2023, which would mean a tripling of the market over five years [11] (p. 1). Experts also claim that 350,000 UAS pilots will be registered by 2023. As of May 2019, there were roughly 1.25 million amateur UAS in the US and that is expected to increase to 1.4 million by 2023 [11] (p. 2). Most recently, the FAA reports that as of 10 March 2020, a total of 1,563,263 UAS have been registered (441,709 commercial UAS and 1,117,900 recreational UAS) and 171,744 remote pilots have been certified [12] (p. 1). Furthermore, the FAA predicts that air traffic will continue to increase 1\% per year for the next 21 years [13] (p. 27).

FAA/NASA UAS Traffic Management Program: In response to the need for safely integrating UAS into the US National Airspace System, the FAA, in conjunction with NASA, implemented a joint program to manage this effort. The program, titled the UAS Traffic Management (UTM) system, was led via a FAA/NASA Research Transition Team (RTT). NASA took primary lead for the initial program with a series of flight campaigns focused on identifying and developing suitable technologies, tools, and procedures that would eventually allow Small UAS (sUAS) to operate safely within the NAS. The FAA focused on operationalizing the most promising technologies, tools, and procedures to develop more realistic planning scenarios and concepts of operation for implementation or further study.

NASA UTM campaigns were named according to increasingly [14] (p. 1) complex Technical Capability Levels (TCLs) shown in Figure 2, moving from initial demonstrations of low-density UAS operations in sparsely populated rural areas (TCL1) and incrementally moving towards high-density, highly interactive scenarios requiring increased levels of UAS autonomy and system integration (TCL4).

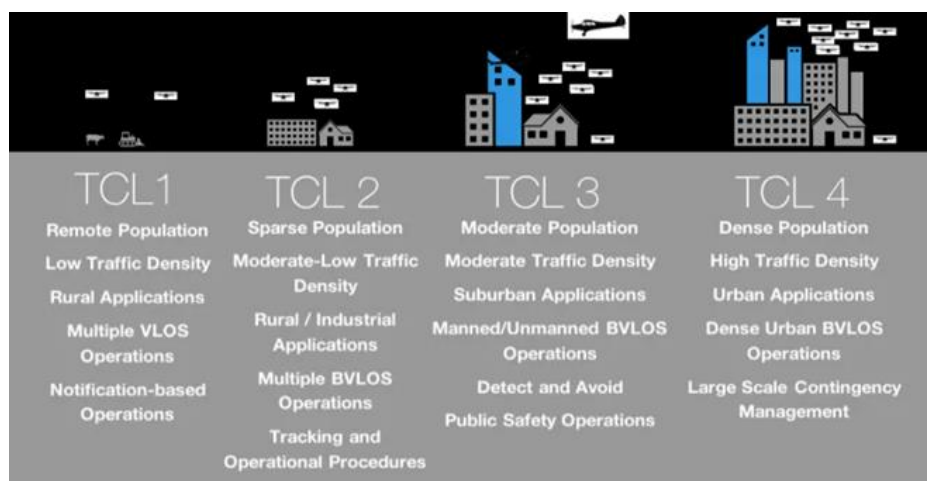

Figure 2. NASA UAS Traffic Management (UTM) Technical Capability Level (TCL) capabilities [15] (p. 11). 
The FAA UTM flight campaigns, titled the UTM Pilot Program (UPP) provided realistic scenarios for expected UAS/manned aircraft operations to determine the appropriate next steps toward the development and deployment of prototype enterprise services into the FAA framework [16] (p. 1). "UTM services demonstrated in UPP Phase One included: (1) the exchange of flight intent among operators, (2) the generation of notifications to UAS Operators regarding air and ground activities, known as UAS Volume Reservations (UVRs), and (3) the ability to share UVRs with stakeholders, including other UAS Service Suppliers (USS) and the Flight Information Management System (FIMS)". UPP2 objectives include testing of Remote Identification (RID) technologies and operations with increasing volumes and density in cooperation with NASA, FAA UAS Test Sites, industry stakeholders, and UAS IPP participants [17] (p. 1).

UAF organizational interest in UTM: In December 2013, UAF's Alaska Center for Unmanned Aircraft Systems Integration (ACUASI) was selected as one of the six FAA UAS test sites established by the 2012 FAA Modernization and Reform Act. The Pan Pacific UAS Test Range Complex (PPUTRC) reports to ACUASI, but also includes principal partners in Oregon and Hawaii as well as 56 non-state partners located across US and internationally. Figure 3 shows locations of the PPUTRC major ranges and partners.

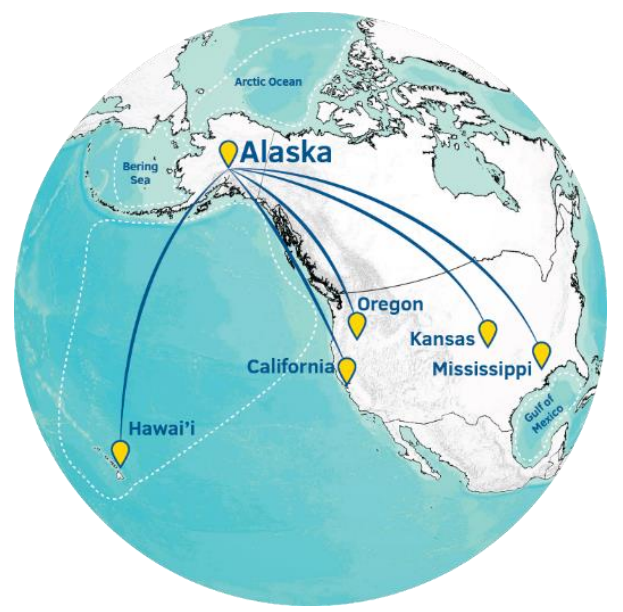

Figure 3. University of Alaska Fairbanks (UAF)/ Alaska Center for Unmanned Aircraft Systems Integration's (ACUASI's) Pan Pacific UAS Test Range Complex (PPUTRC) partner locations [18] (p. 1).

In May 2018, UAF was named as one of the 10 Integration Pilot Program (IPP) teams by the Department of Transportation (DoT) and Federal Aviation Administration (FAA). The team's 21 partners include UAS manufacturers, technology developers, operators and public and private end users from Alaska and the rest of the US. The team's charter focuses primarily on monitoring pipelines, roads and other linear infrastructure, and also includes areas such as delivering medical devices to remote areas, helping search and rescue (SAR) efforts, and surveying fish and wildlife. In support of these missions, UAF has been granted authority by the FAA to conduct true BVLOS operations. UAF was selected for UTM participation and to support the development, design, and testing of the TCL1, TCL2, and TCL3 campaigns. This paper describes the UTM program goals and accomplishments integrating UAS into NAS in Western US accomplished by the ACUASI team.

\section{Materials and Methods}

The UTM system architecture shown in Figure 4 highlights the major components needed to fly a particular mission within airspace reserved for this purpose, including local volume or multiple legs of a Beyond Visual Line-Of-Sight (BVLOS) route, the UAS operator, the UAS Service Supplier (USS), Supplemental Data Service Provider (SDSP), and the Flight Management Information System (FIMS). The UAS operator is responsible for requesting airspace volumes and times, operating the 
UAS safely and within the parameters governing the UAS within this airspace, recording the times of takeoff/landing, and noting any remarkable or abnormal events during the flight (e.g., incursion of other UAS or aircraft into the airspace and inflight emergencies).

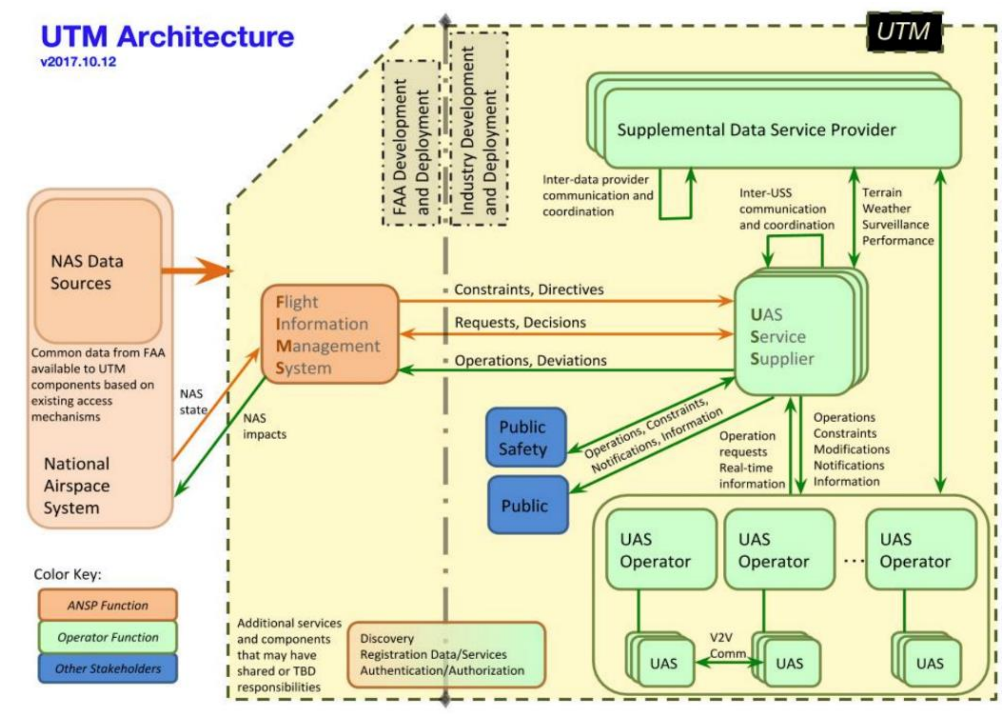

Figure 4. UTM architecture [19] (p. 9).

The USS serves as the primary link between the UAS operator and the central FIMS, forwarding airspace requests and UAS position information to the FIMS and returning airspace request status, emergency notifications, and other airspace picture information to the UAS operator. The SDSP provides an additional layer of information for some missions, such as local weather and terrain data. The FIMS is the central core of the UTM system, responsible for maintaining the overall air picture, deconflicting missions, approving/modifying airspace, tracking UAS flights, and advising USS providers of high-priority UAS or manned aircraft missions.

The UTM system provides for two levels of data portals into UAS operations, accessible at the USS provider level. The public portal allows the general public to visualize generic information on the UAS flying in the local area or other locations. The public safety portal allows public safety officers access to additional information about the UAS missions (e.g., owner and contact information). USS providers may communicate via the FIMS and relay a request for information regarding UAS under the control of other USS providers.

In examining a conceptual overview of how the UTM elements might interact in support of a typical mission, Figure 5, multiple USS providers are located throughout an area in support of various UAS operators and are in constant communication with both their UAS operators and the centralized FIMS. In addition, the USS providers are registered within a centralized USS Discovery Service and may be made aware of one another for the purposes of resolving emerging airspace issues (e.g., incursion of a UAS from its approved airspace into another airspace due to vehicle malfunction or extreme weather).

Table 1 summarizes UAF/ACUASI's participation in the UTM program. Campaigns were primarily performed at UAF's main campus and the Poker Flat Research Range (PFRR). TCL2a was a centralized effort performed under NASA's supervision at Reno-Stead Airport in Nevada. UAS employed were all in the small UAS (sUAS) category (under $55 \mathrm{lbs}$.), and all were either single rotor (ING Responder) or multirotor UAS, with the exception of the Aeromao Aeromapper fixed-wing UAS utilized in TCL1. UAS were selected for the missions based on their ability to support mission objectives, flexibility in performing various roles, reliability/availability of parts, ease of use, and cost. 


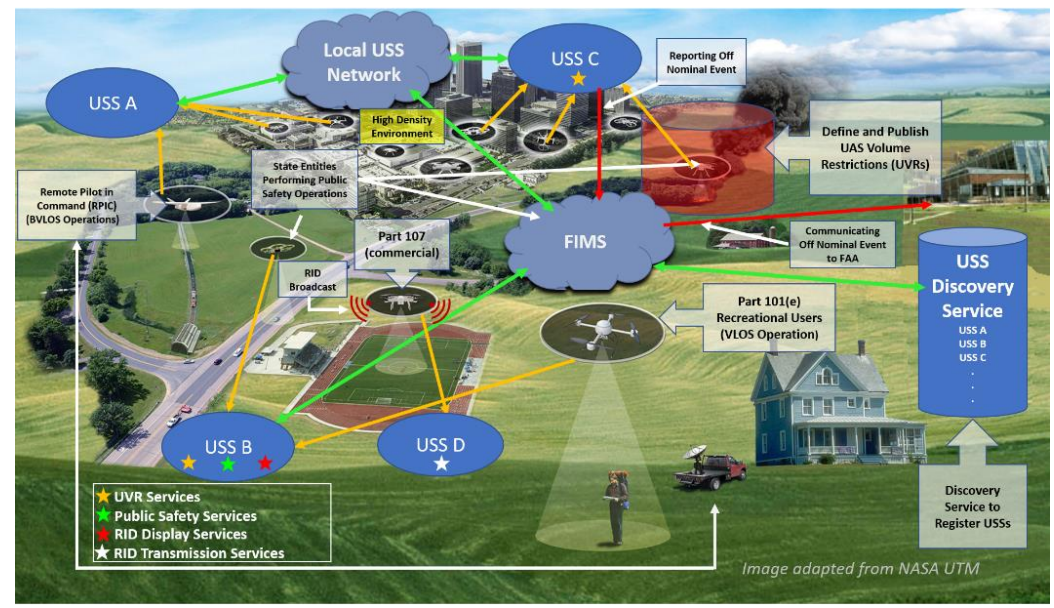

Figure 5. FAA UTM Pilot Program (UPP) conceptual overview [17].

Table 1. UAF/ACUASI participation in UTM TCL1-3 campaigns.

\begin{tabular}{|c|c|c|c|}
\hline UTM Phase & Dates and Location & Program Focus & UAS Employed \\
\hline TCL1 & $\begin{array}{l}\text { May } 2016 \\
\text { UAF PFRR }\end{array}$ & $\begin{array}{l}\text { Demonstration of simultaneous } \\
\text { flight and tracking of multiple UAS } \\
\text { at test sites across the country. }\end{array}$ & $\begin{array}{l}\text { Aeromao Aeromapper } \\
\text { ING Responder } \\
\text { S800 Ptarmigan }\end{array}$ \\
\hline TCL2a & $\begin{array}{c}\text { October } 2016 \\
\text { Reno-Stead Airport }\end{array}$ & $\begin{array}{l}\text { Demonstration of multiple agencies } \\
\text { and operators employing dissimilar } \\
\text { UAS in close quarters. }\end{array}$ & UAF: S800 Ptarmigan \\
\hline TCL2b & $\begin{array}{c}\text { May/June } 2017 \\
\text { UAF Campus and PFRR }\end{array}$ & $\begin{array}{l}\text { Demonstration of multiple UAS } \\
\text { being employed in proximate } \\
\text { airspace, including } \\
\text { altitude-stratified BVLOS corridors. } \\
\text { Exploration of potential automated } \\
\text { Sense And Avoid (SAA) protocols } \\
\text { and technologies. }\end{array}$ & $\begin{array}{l}\text { ING Responder } \\
\text { S800 Ptarmigan } \\
\text { S900 Hexacopter } \\
\text { S1000 Octocopter } \\
\text { DJI Inspire 1 } \\
\text { DJI Matrice } 100\end{array}$ \\
\hline TCL3 & $\begin{array}{c}\text { May } 2018 \\
\text { UAF Campus }\end{array}$ & $\begin{array}{l}\text { Same as TCL2b. Increased emphasis } \\
\text { placed on UAS tracking and } \\
\text { automated UAS deconfliction with } \\
\text { manned aircraft and other UAS via } \\
\text { SAA technology. }\end{array}$ & $\begin{array}{l}\text { ING Responder } \\
\text { S800 Ptarmigan } \\
\text { S900 Hexacopter } \\
\text { S1000 Octocopter } \\
\text { DJI Inspire 1 } \\
\text { DJI Matrice } 100\end{array}$ \\
\hline
\end{tabular}

A central tenet in UAF's strategy for the UTM program has been to work in areas that will both benefit NASA/FAA and those mission sets and capabilities in which the test site is vested. As such, the team focused efforts on increased support for Beyond-Visual-Line-of-Sight (BVLOS) flights in high-latitude locations, such as is common in Alaska. This includes systems enabling improved navigation and long-range communications, as well as tools supporting multiple simultaneous UAS operations and increased ability to operate in cooperation with geofences. Through this and related efforts, UAF achieved a majority of the initial technical and operational goals outlined in the mission sets.

UTM TCL1 campaign: Using the crawl, walk, run approach, testing began with relatively sparse UAS operations in either remote or lightly populated urban areas. The basic requirements for this phase included the ability for a UAS crew to request and reserve a defined volume of airspace, for the UAS to be capable of reporting its position to NASA, for mission durations to be tracked, and for the system status of UAS to be logged (ready, airborne, rogue, landed, and mission terminated). The interface for communications was provided through a UAS System Services (USS) provider. Selected excerpts from the NASA TCL1 Statement of Work (SoW) are provided in Appendix A. 
The UTM TCL1 campaign and flight demonstration occurred in May/June 2016. The overarching focus for this effort was to demonstrate the ability for the UTM system to support coordination with UAS operators located across the country and to simultaneously track these geographically diverse operations. All six participating FAA UAS test sites (Alaska, Nevada, Texas, North Dakota, Virginia, and New York), Figure 6, each flew four UAS, for a total of 24 UAS simultaneously flown across the country. The flight paths of all UAS were depicted in real-time at the NASA Ames Research Center UTM program office, Figure 7.

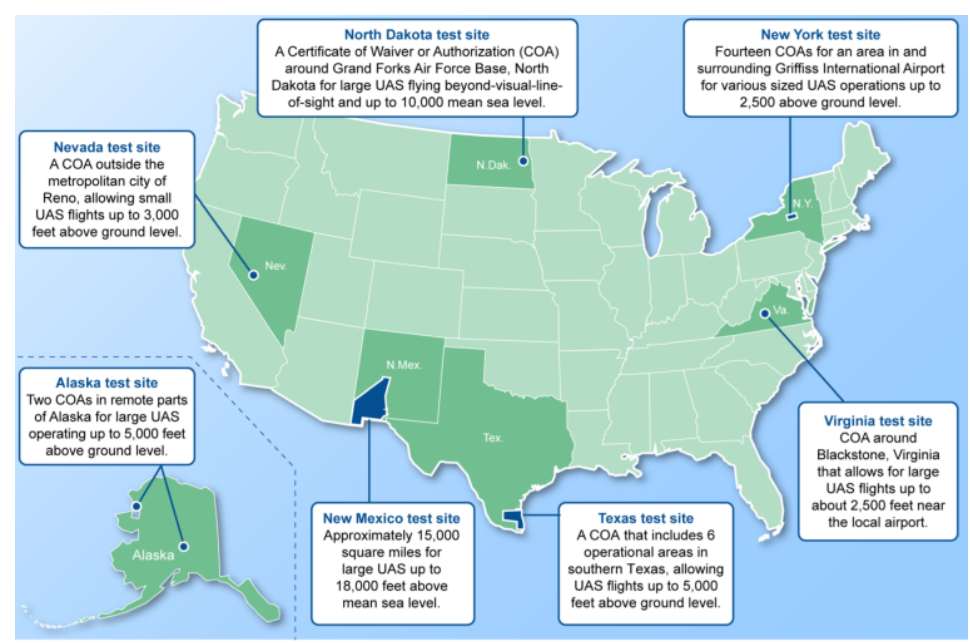

Figure 6. FAA UAS test sites participating in the UTM program and sample of the existing test sites' certificate of authorization locations and allowable unmanned aircraft system operations, as of October 2019 [20] (p. 11).

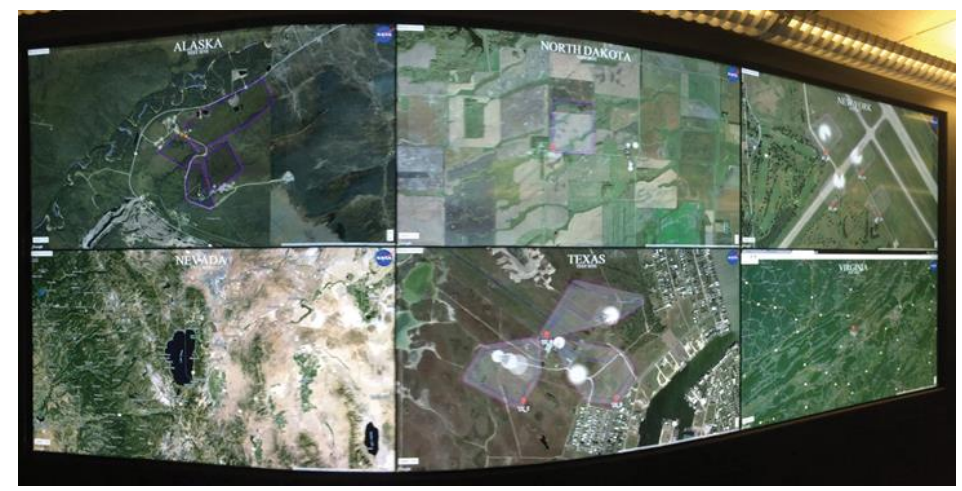

Figure 7. NASA Ames UAS operations for UTM TCL1 [21].

UAF was able to fly four UAS simultaneously, with two vehicles separately flown from two distinct launch locations at the Poker Flat Research Range (PFRR), Figure 8A. One flight team operated a Ptarmigan S800 hexacopter (foreground of Figure 8B) and an Aeromao Aeromapper fixed-wing UAS from a low-altitude location in the valley of PFRR. A second team operated the ING Responder single-rotor helicopter (background in Figure 8B) and another Ptarmigan in adjoining airspace located up on the ridge line of PFRR overlooking the valley from approximately $200 \mathrm{ft}$ altitude above the valley floor. 

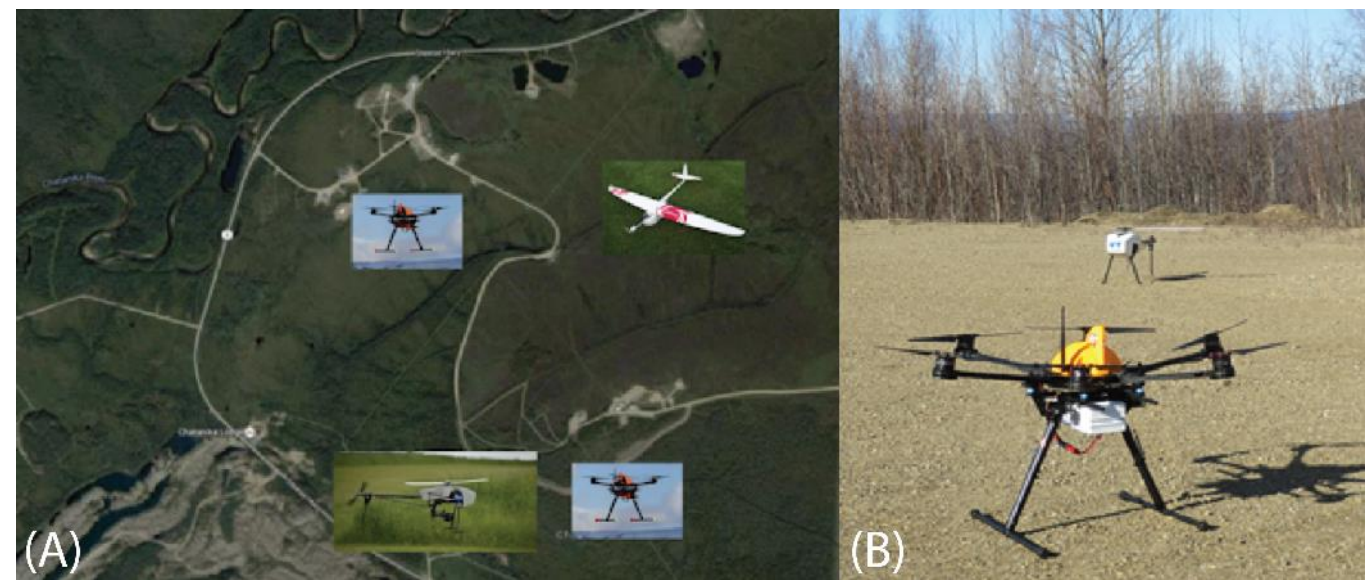

Figure 8. (A) NASA TCL1 Campaign Flight Assets and Locations; (B) ACUASI Ptarmigan S800, ING Responder.

UAF's flight operations manager coordinated and controlled flight operations via radio communications with ground pilot teams and UAF's test manager. The test manager coordinated overall activities with NASA UTM personnel (telephone and internet), USS provider (voice and written notes), and the flight operations manager (radio). Details of the UAS/USS/UTM data communications are provided in Figure 9.

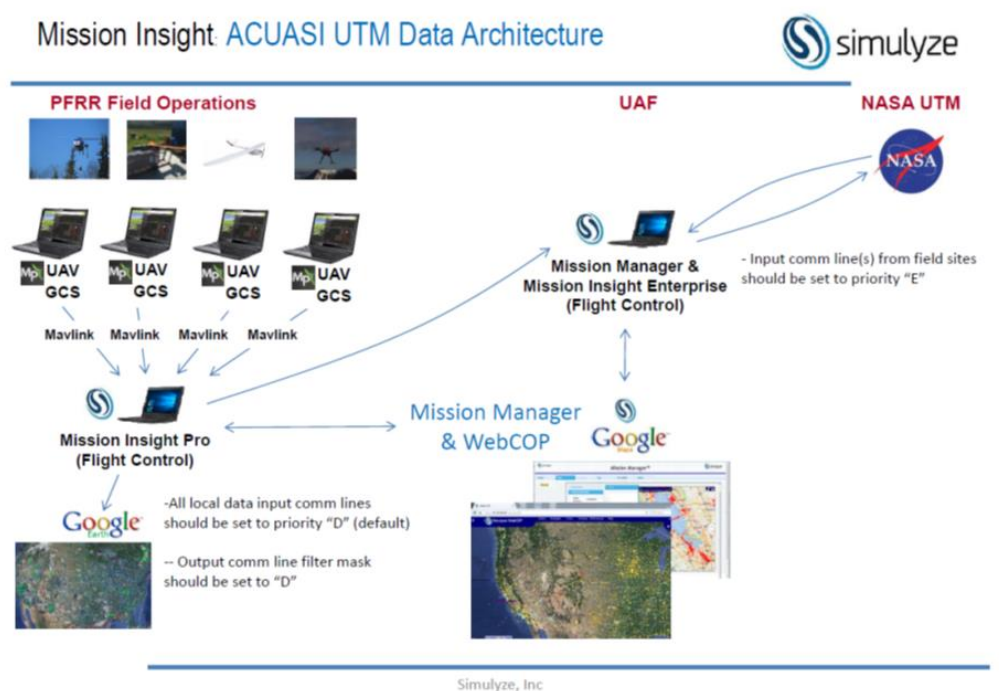

Figure 9. UTM architecture for UAF TCL1 [22] (p. 9).

The TCL1 demonstration was scheduled for the period of 19-21 April 2016, with the primary flight operations scheduled for 19 April/0800-1200 (AST). The flight operations period was divided up into three time windows: $0800-0900$ hrs, $0900-1000$ hrs, and 1000-1100 hrs. During each of these windows, each test site attempted to simultaneously operate four UAS locally. NASA stated criteria for a fully successful campaign was to have a total of 24 UAS at the six test sites performing concurrent flight operations.

UAF employed a variety of UAS types for the TCL1 campaign.

- $\quad$ Single-rotor UAS. The ING Responder is a helicopter design based on the Gaui X7 frame and PixHawk autopilot.

- Multi-rotor UAS. The ACUASI Ptarmigan is a hexacopter based on the DJI S800 frame and 3DR APM (PixHawk predecessor) autopilot. Relatively short flight times for the Ptarmigan required the UAS be recovered half-way through each flight window, then relaunched with a fresh battery. 
- Fixed-wing UAS. The Aeromao Aeromapper was the only fixed-wing UAS used for TCL1 and gave UAF an asset with further reach and significantly different flight performance characteristics.

UAF utilized the Simulyze UTM Client interface to pass UAS data to the NASA UTM system. Simulyze was employed by several test sites and their system was well known by NASA. UAF's selected implementation was a single instance of the client simultaneously coordinating data for all four UAS. Figure 9 is a schematic depicting the system architecture.

This same UTM structure was utilized by UAF during the NASA UTM TCL2 and TCL3 campaigns. A single instance of the Simulyze UTM manager was employed to input mission data (e.g., UAS vehicle identification, mission start/stop times, and status) in most cases. During some missions, multiple instances of the UTM manager were employed due to simultaneous operations involving distant locations or large numbers of UAS. As the campaign progressed, the Simulyze UTM Manager was deployed as a helpful situational awareness tool to pilots (e.g., visual indication of flight area boundaries and incursions by an aircraft or other UAS).

UTM TCL2 campaign: This phase of the program consisted of two separate flight campaigns. The first event included a selectively identified (by NASA) set of agencies participating in a centralized flight demonstration held at Reno-Stead Airport in October 2016. The major portion of the TCL2 campaign was a follow-on series of events occurring at each selected UAS test site in May/June 2017.

During the Reno-Stead demonstration, NASA coordinated three sets of tightly integrated flight scenarios (Figure 10A) to be conducted between five different flight crews involving dissimilar UAS, all operating within close quarters. This provided insights into the level of coordination (both manual and autonomous) that might be required for future scenarios involving multiple different agencies and pilots conducting mixed operations utilizing a mix of UAS with various performance characteristics. UAF participated in two of the three combined scenarios using the ACUASI Ptarmigan S800 hexacopter, Figure 10B.

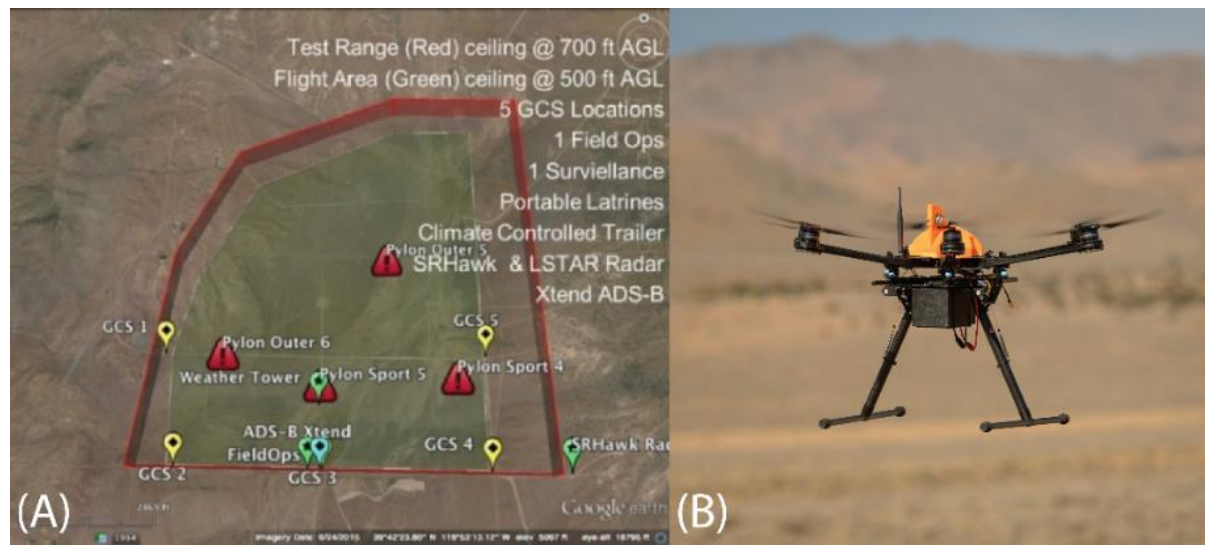

Figure 10. (A) NASA TCL2 campaign at Reno-Stead, October 2016 [23] and (B) ACUASI Ptarmigan S800 UAS. [23].

The second phase of the UTM program focused on sets of identified functional objectives. The overall set of mission tasks were spread between the various partner entities with consideration to workload, technical approach, teaming arrangements, and geographical and environmental considerations. Highlights from the TCL2 SoW are listed in Appendix A. UAF was selected to work directly on the communication, navigation, surveillance (CNS), and geofencing technologies/conformance monitoring sections of the SoW. The team also indirectly supported other NASA priorities, including USS technologies and procedures and human factors related to UTM data creation and display.

Over the period of 15 May-9 June 2017, several flights were conducted at PFRR and UAF main campus locations as part of system capability testing, shakedown tests, and demonstration. UAF's 
TCL2 primary flight campaign demonstration occurred 5-9 June. UAS assets used for the missions included ACUASI's Ptarmigan S800 hexacopter, S900 hexacopter, S1000 octocopter, ING Responder helicopter, DJI Inspire 1 quadcopter, and DJI Matrice 100 quadcopter.

The TCL2 flight campaign consisted of four scheduled flying days with a built-in makeup day. Flight profiles were scheduled for both an AM block and a PM block to support testing logistics.

Day 1 scenario. Here, four different UAS conducted simultaneous operations, with two UAS conducting extended-visual line of sight (EVLOS) altitude-stratified flight operations and two UAS conducting local operations utilizing a combination of altitude-stratified and geographically contiguous airspace. The two UAS conducting EVLOS altitude-stratified flights along the corridor (green and purple areas) simulated a pipeline survey/inspection mission. The UAS conducting low local operations at Herder Burner (blue area) simulated either a SAR mission or vegetation mapping mission, depending upon the sensor flown. The hillside mission (brown area) simulated a dinosaur fossil mapping or glacier mapping mission (both were rehearsals for actual missions to be performed later that summer).

Flights accomplished included four simultaneous UAS: one sortie in high-altitude block (650-850') EVLOS along the corridor (Responder); one sortie in mid-altitude block (250-550') EVLOS along the same corridor (Matrice); one sortie in low-altitude block (0-250') stratified local airspace (Ptarmigan); and one sortie contiguous airspace (0-500') local operations (S1000). These flights were conducted in both the AM/PM time blocks using the airspace shown in Figure 11.

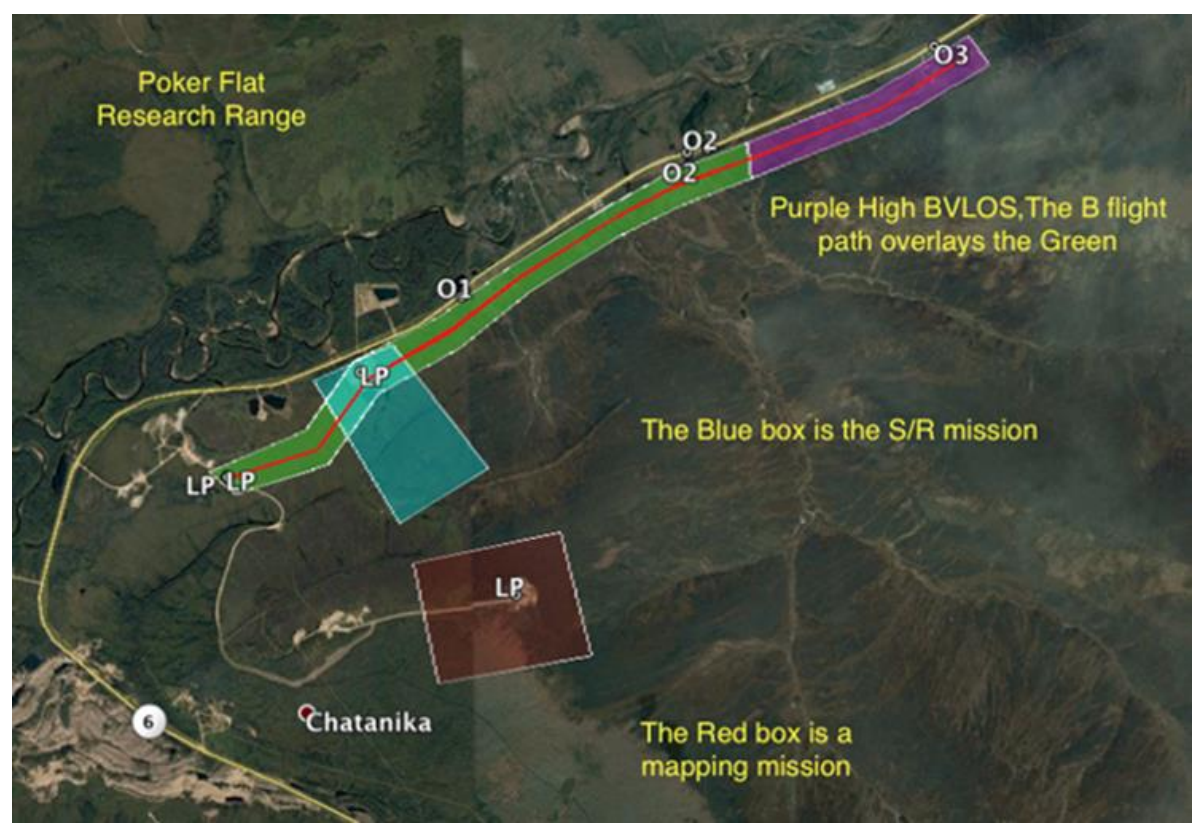

Figure 11. UAF TCL2 campaign at the Poker Flat Research Range (PFRR), May 2017. UAF assets included 1× each Ptarmigan S800, S900, S1000, ING Responder, and DJI Matrice 100, DJI Inspire [22] (p. 10).

Day 2 scenario (media day). This mission set included up to five different UAS conducting simultaneous coordinated geographically separated operations, 1-2 at UAF campus and 1-2 at PFRR. The AM mission at UAF included videography of the new Elvey $9 \mathrm{~m}$ satellite dish by a S800 Ptarmigan UAS, as well as an airborne video of the mission taken by a DJI Inspire. The PM mission at UAF involved a lakeshore mapping of Smith Lake. The simultaneous AM mission at PFRR was the demonstration of a parachute system for multirotor UAS (S900 hexacopter). PM missions at PFRR involved an airborne SAA demonstration and Real-Time Kinematic (RTK) GPS work (S1000 octocopter).

For the UTM/USS implementation, UAF selected a semicentralized approach using one UTM Point of Contact (POC) at UAF and a second UTM POC at PFRR locations. Simultaneous operations for UAF and PFRR were achieved by coordinating launch times in advance and then communicating via 
text. Flight operations at PFRR were conducted in close proximity as shown in Figure 11. The airspace utilized for UAF site missions is shown in Figure 12A. The ACUASI Ptarmigan hexacopter performing the inspection is shown in Figure 12B.

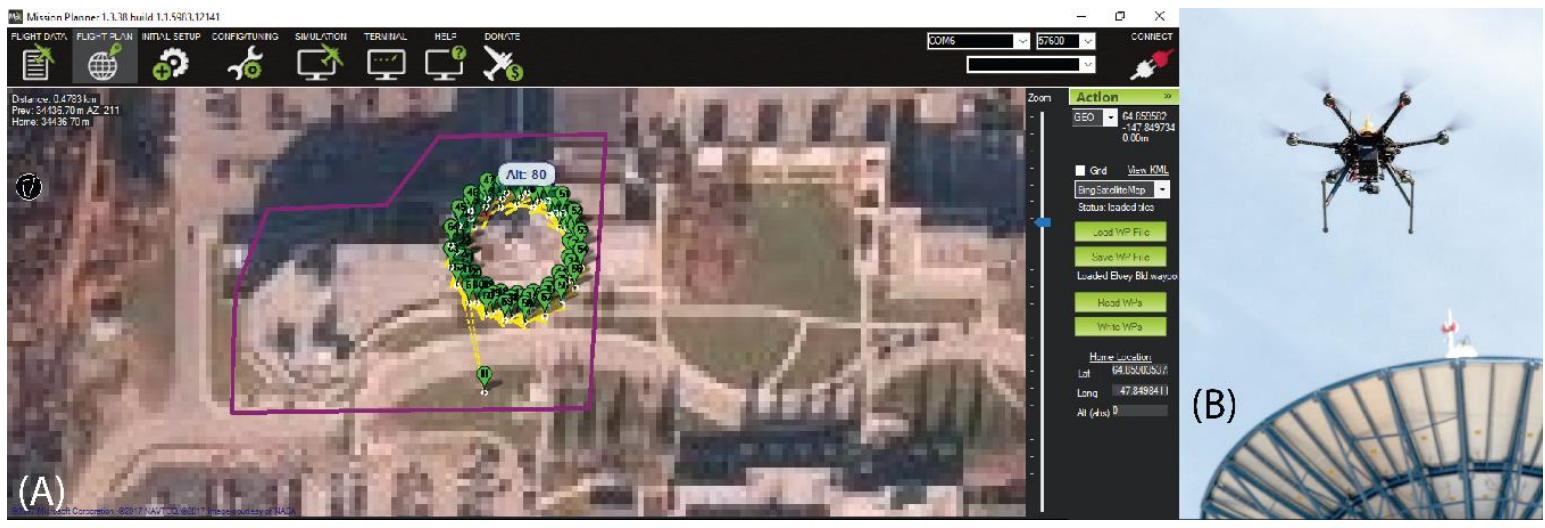

Figure 12. (A) Flight points for video survey of the Elvey $9 \mathrm{~m}$ satellite dish and (B) ACUASI Ptarmigan UAS; photo courtesy of Eric Engman, News-Miner (C2017. [24].

Flight activities during days 3 and 4 were similar to that of the day 1 scenario, but with varying altitude blocks and UAS involved. These days were also used for weather makeup, as both snow (even in June) and wind had often curtailed planned flight activities.

UTM TCL3 campaign: The third phase of the UTM program focused on more technically complex systems, which would begin to provide increasingly automated UAS/USS system capabilities to handle the additional complexities associated with higher-density UAS traffic and interactions. NASA asked the UAS test sites to consider which aspects they would focus on for their respective efforts and used a competitive bid process, enabling NASA to spread the effort between the various entities based upon the program interests and team capabilities. Highlights from the TCL3 SoW are listed in Appendix A.

TCL3 included a series of distributed events occurring at several UAS test sites. For this campaign, UAF changed locations for flight operations from PFRR to the grounds adjacent to the UAF's main campus. The flight airspace was divided into complex and tightly integrated geometries to increase the airspace density and UAS interaction above previous TCL2 levels. Tasks were divided into sets of major categories: (1) CNS: Communication, Navigation, and Surveillance; (2) SAA: Sense And Avoid; (3) DAT: Data and Information Exchange; and (4) CON: Concepts. UAF was selected to work on CNS1, CNS2, CON1, CON2, CON3, CON4, CON5, SAA2, and SAA4. In addition, UAF provided support to NASA for SAA3 and DAT5. An overhead perspective of the airspace blocks used for TCL3 is shown in Figure 13A; 3-dimensional perspectives of the airspace are shown in Figure 13B,C.

UAF's TCL3 flight campaign was conducted during the period of 23 April-30 May 2018. In general, most flights profiles were scheduled to occur within a time block from 1000 to 1400 hrs (local). This sequencing allowed for a mission briefing each morning (0830 hrs) and setup of UAS assets, communications gear and computer networking, conduct of the mission, teardown and recovery, and then conduct of end of day mission debriefings (typically $1500 \mathrm{hrs}$ ). The sequencing and details of particular flight days evolved over time as a result of several factors, including coordination between UAF and NASA, experiences learned through the planning process and the developmental flight test campaign, and at times due to resource or personnel availability. Flight plans evolved over the course of the campaign to take advantage of weather conditions, experience gained during operations and shakedown tests, and NASA program desires. A discussion of flights is provided below.

CNS1, maintaining control of UA with redundant C2: The purpose of this test was to determine the effect of primary versus secondary communications link timing on UAS performance. For UAF's CNS1 task, two different UAS were to be utilized: (1) At UAF, a F450 quadcopter UAS was tested in two different configurations: (a) two $900 \mathrm{MHz}$ radios and (b) one $900 \mathrm{MHz}$ radio vs. a Long-Term Evolution 
(LTE) 4G cellular radio. (2) In addition, UAF planned to conduct tests on its newly acquired Griffon SeaHunter UAS either at Alma, Quebec (where the flight test was already scheduled for spring 2018) or at a later time back in the United States. The SeaHunter UAS possesses three separate communications links: $900 \mathrm{MHz}$ radio, $2.4 \mathrm{GHz}$ radio, and iridium satellite communications. Note: This test was later cancelled due to a lack of availability of the SeaHunter during the TCL3 flight campaign.

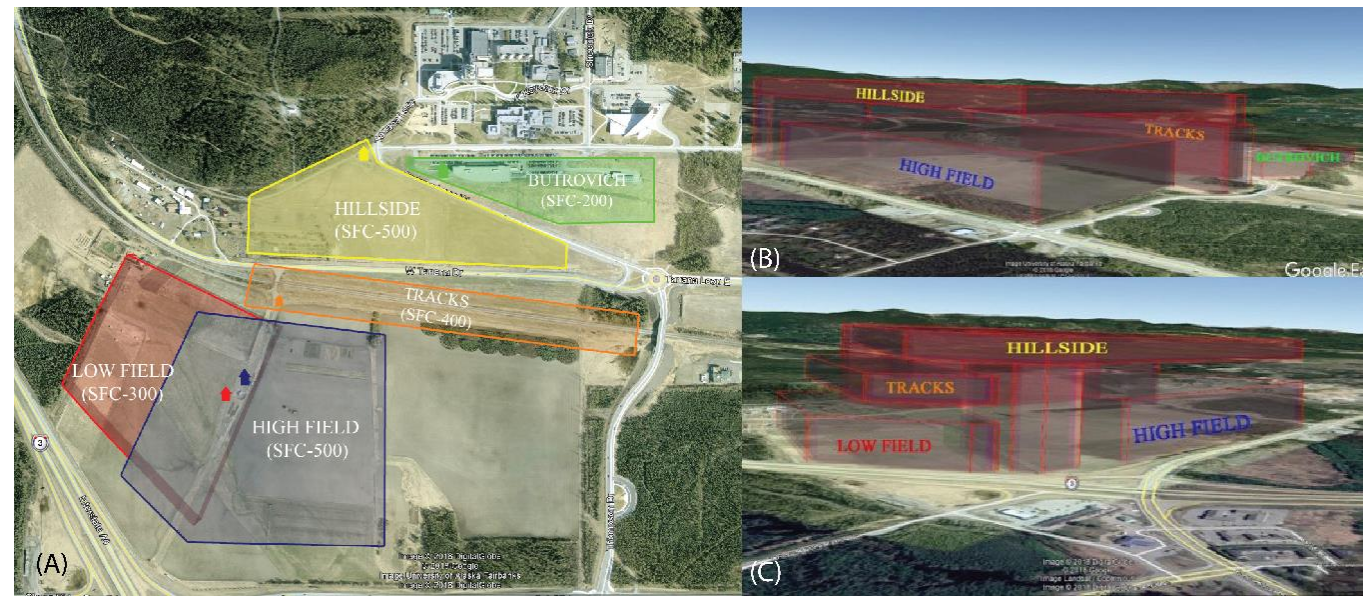

Figure 13. (A): Overhead view of baseline airspace volumes for UTM TCL3 and (B,C) 3D views of airspace.

CNS2, remaining within flight geography using GNSS navigation: The purpose of this test was to determine the effect of GPS/GNSS satellite degradation due to masking by natural terrain or man-made objects. For this task, UAF planned to utilize a S1000 octocopter as the flight vehicle and a newly acquired EchoDyne MESA ${ }^{\circledR}$-SSR ground radar as the 'truth source' for the flights. The focus of the task was to determine: (1) the ability to correlate ground radar tracks with UAS position as closely as possible under ideal conditions and (2) determine the effects of degraded GPS/GNSS signals due to terrain features or man-made structures. Note: While UAF was able to complete a valuable analysis and modeling of the GNSS signals at high-latitude, with recent upgrades to both the GNSS constellations and the UAS receivers, the signal degradation never proved significant in the rural terrain or urban city environments tested.

CON1, BVLOS landing: The purpose of this test was to demonstrate the ability of a UAS to autonomously conduct a BVLOS landing and subsequent take-off and return to base. This operation was conducted several times in various scenarios, incorporating different locations, distances, and numbers of remote landing/takeoff points. These were conducted, both as primary data collection missions for CON1, as well as supplementary missions added to enrich other scenarios (CON4 and CON5). Figure 14A shows the S1000 octocopter performing a BVLOS landing $1 / 2$ mile from the operator. Figure 14B shows the S1000 after landing in a 2 nd location, again $\sim 1 / 2$ mile from the operator. Figure $14 \mathrm{C}, \mathrm{D}$ show distances measured from surveyed target locations vs actual landing points (marked by coins) at a site $\sim 1 / 4$ mile from the operator.

CON2, contingency initiation: The purpose of this test was to demonstrate the ability to interrupt current operations with a scripted UAS emergency necessitating activation of a prepared contingency. Actions demonstrated included: loiter well clear of the contingency operations, direct/immediate return to base (RTB), and "ditch" at a known location using parachute recovery. For efficiency of operations, flights for CON2 were designed to be conducted with interactive courseware for CON4 flight scenarios. Figure 15A shows the S900 hexacopter under canopy during a simulated "ditch" scenario; Figure 15B shows the $S 900$ immediately after landing. 


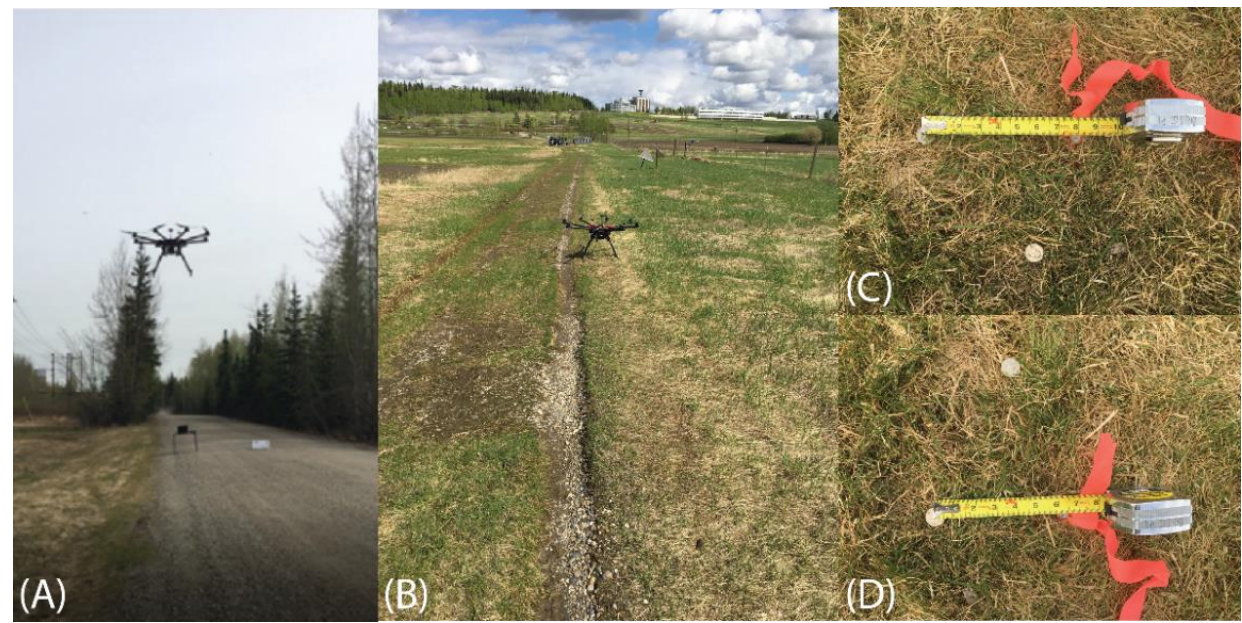

Figure 14. (A) F550 landing remotely at site $\frac{1}{2}$ mile away; (B) S1000 landing at site $\frac{1}{2}$ mile away (launch site at top of hill in background); and (C,D) measurements showing landing of F550 vs. the surveyed point from $\frac{1}{4}$ mile away.

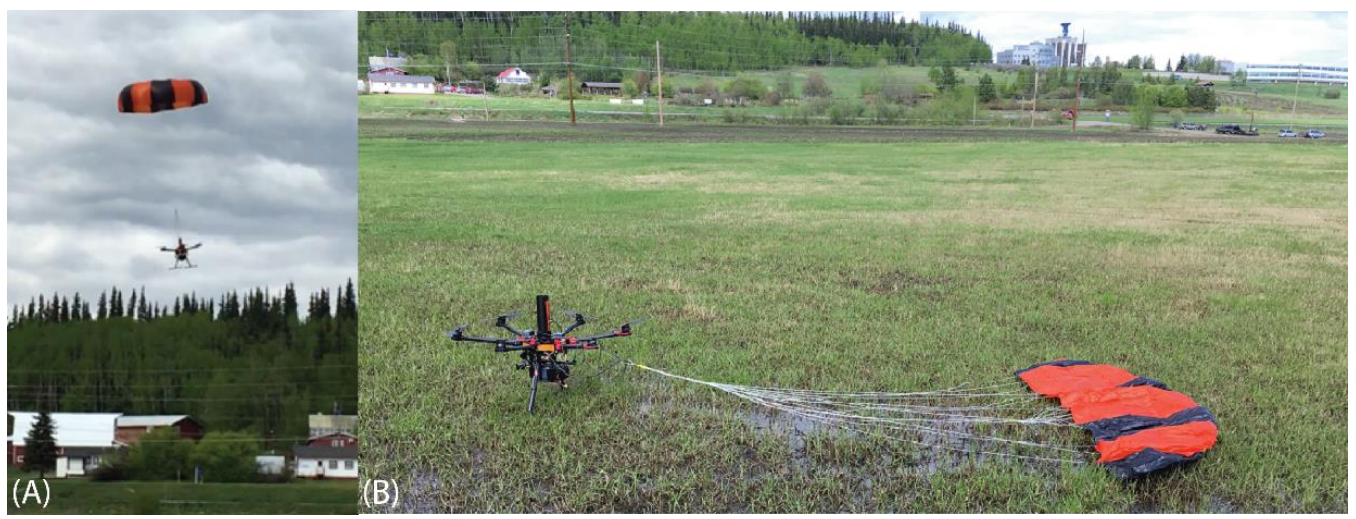

Figure 15. (A) S900 hexacopter under canopy and (B) S900 after landing.

CON3, public portal: The purpose of this test was to develop a USS client browser and/or app-based mechanism for an anonymous member of the general public to access appropriate UTM information, and to evaluate its effectiveness through a usability study. This test was designed to utilize previously recorded flight test data (CON1/2/4/5) with both public portal and public service provider interfaces used for monitoring of UTM activity. Note: UAF was unable to complete this activity due to the schedule and repurposing of NASA UTM assets required for the development of new USS interfaces.

CON4, multiple TCL-2/3 operations for a sustained period: The purpose of this test was to demonstrate the ability of the test site operator (TSO) to fly multiple TCL-2/3 operations for a sustained period (e.g., 2 hrs). The TSO was to conduct an extended scenario with multiple interacting TCL-2/3 operations (e.g., multiple deliveries, traffic monitoring, infrastructure inspection, and real estate photography), and demonstrate that these can be conducted safely in the same airspace in a more realistic dynamic environment. For the efficiency of operations, flights for CON2 were conducted ICW with CON4 flight scenarios.

CON5, FIMS/USS interaction when a vehicle heads towards controlled or unauthorized airspace: The purpose of this test was to demonstrate an appropriate FIMS/USS interaction when a UAS heads towards controlled or unauthorized airspace. The TSO was to conduct a test where a UAS flies out of its operations volume and heads towards controlled airspace, and to demonstrate/evaluate the necessary FIMS/USS/UAS interactions supporting the scenarios. UAF was elected to demonstrate two separate categories of scenarios for CON5: (1) statically controlled airspace typically associated with traditional 
manned or UAS flight scenarios and (2) dynamically allocated high priority controlled airspace as a result of emergency operations (e.g., medical evacuation or delivery of critical life-saving supplies). Figure 16A shows airspace selected for the statically controlled airspace mission; Figure 16B shows the airspace used for the dynamically controlled scenario. For the efficiency of operations, flights for CON5 were originally designed to be conducted ICW with CON4 flight scenarios. Originally, CON4 flights were to be flown on two consecutive days, followed by the introduction of simulated contingencies comprising of CON5 scenarios. However, compression of the flight timeline due to weather delays and engineering/communications challenges caused the CON2/4/5 scenario durations and sequencing to be modified to achieve desired flight results for each without jeopardizing the overall flight schedule. As a result, initial CON5 scenarios were conducted ahead of time, separate from the larger CON4 scenarios (scheduled 21-25 May) to take advantage of good weather conditions, though with a lesser number of UAS due to limited flight crew availability.

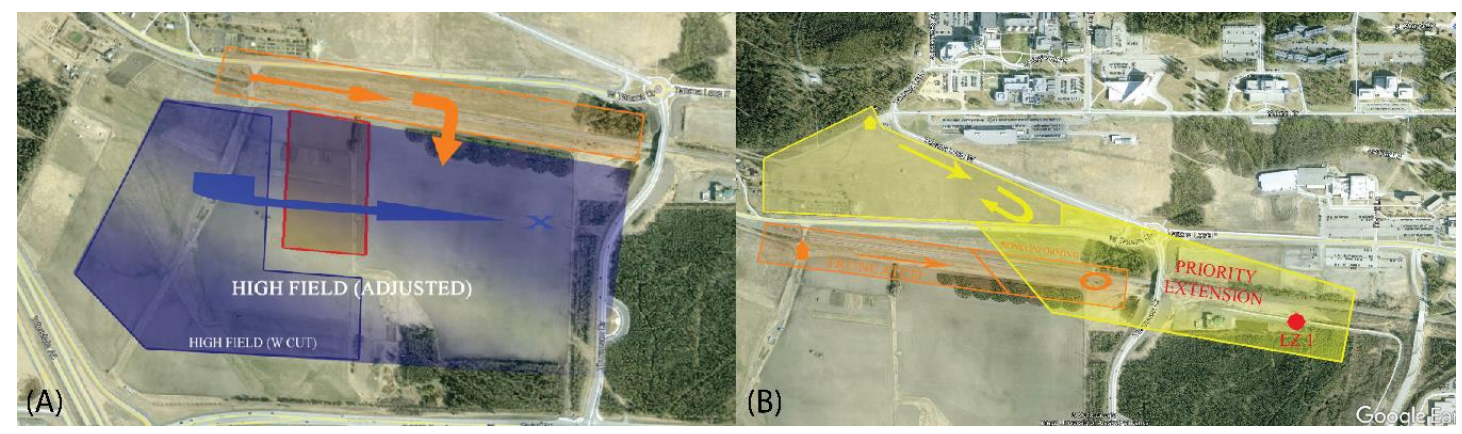

Figure 16. (A) Airspace for the statically controlled airspace allocation scenario and (B) airspace for the dynamically controlled airspace allocation scenario.

SAA2, conflict mitigation cooperative technology for the UAS-manned interaction: The purpose of this test was to demonstrate the ability to detect airborne conflicts and resolve these utilizing an information broadcast by Automatic Dependent Surveillance Broadcast (ADS-B) technology. UAF's approach for all SAA missions was to use a 'crawl, walk, run' approach beginning with manual control of functions and progressing, as able, through incrementally increasingly autonomous behavior with a 'reach goal' of achieving fully autonomous behavior. The S1000 UAS was flown with the ADS-B to characterize its ability to accurately communicate and report its position to the Ground Control Station (GCS) via MAVLink, as displayed on Mission Planner GCS. Next, two UAS with ADS-B were flown simultaneously to determine the ability of the UTM system to accurately communicate with GCS and between the two UAS. Finally, the two UAS were flown in various cooperative profiles to determine the UTM system's ability to report relative positional information to the GCS, and determine both the operators' ability to manually perform separation/evasive UAS maneuvers and for the UAS to perform automatic Airborne-Based Detect And Avoid (ABDAA). To support this capability, UAF integrated an ADS-B unit with a S1000 Pixhawk to allow for ADS-B proximity data to command maneuvers. UAF's S1000 had already incorporated RTK GPS and a laser altimeter system for increased accuracy navigation. Immediately following the formal TCL3 flight campaign, UAF successfully demonstrated the ability of the S1000 to hold short of a UAS outfitted with an ADS-B transmitter and for the S1000 to initiate lateral motion away from an aggressing UAS with ADS-B.

SAA3, conflict mitigation non-cooperative technology for the UAS-manned interaction: The purpose of this test was to demonstrate the ability to detect airborne conflicts and resolve these utilizing an information broadcast by optical obstacle avoidance technology. UAF partnered with IRIS Automation ${ }^{\mathrm{TM}}$ to demonstrate the abilities of the IRIS Hedgehog Collision Avoidance Module (HCAM) in providing SAA/ Detect And Avoid (DAA) functionality via optical sensors. As before, UAF proceeded along a 'crawl, walk, run' approach. The first step along this path demonstrated the functionality of the IRIS Automation HCAM system in generating data, which could be used manually 
by UAS flight crews to ensure separation with the encroaching vehicles. Following the success of this first step, it was hoped that the system might later be demonstrated in the autonomous mode.

SAA4, conflict mitigation non-cooperative technology for the UAS-UAS interaction: The purpose of this test was to demonstrate the ability to detect airborne conflicts and resolve them utilizing information obtained from ground radar tracks. Again, UAF's approach utilized a 'crawl, walk, run' approach beginning with the manual control of functions and progressing through incrementally increasingly autonomous behavior with a reach goal of fully autonomous behavior. The S1000 UAS was flown with the MESA-SRR ground radar to characterize its ability to accurately communicate and report its position to the GCS vs. MAVLink and integrate with Simulyze USS. The S1000 was then flown versus a 2nd UAS to determine the ability of the MESA-SSR to accurately detect these and pass this information to GCS. Finally, the two vehicles were flown in various cooperative profiles to determine the system's ability to report relative positional information to the GCS, and determine the operators' ability to manually perform separation/evasive UAS maneuvers and for the UAS to perform automatic DAA based upon commands from ground radar. Immediately following the formal TCL3 flight campaign, the UAF team demonstrated the ability to correlate the S1000 ADS-B signal with its radar track and to convert the radar track into an equivalent ADS-B format message.

\section{Results}

TCL1 demonstration outcomes: UAF successfully participated in the NASA UTM Build 1 UAS Demonstration (19 April 2016). UAF was able to integrate with the NASA UTM Manager and UAS client software suite to submit flight plans, track UAS operations in real-time, and close out flight plans upon termination of flight activities. UAF flew four UAS simultaneously in support of NASA goals for the demonstration. This was a significant accomplishment due to a myriad of challenging factors: (1) the short flight times (10-15 min) of most UAS assets; (2) stringent computer-communications requirements for the effort; (3) limitations imposed by early prototype NASA and third party software; (4) changing weather; and lastly (5) the need to coordinate the aforementioned factors with six test sites in four time zones across the US to get all 24 UAS in the air simultaneously.

UAF was successful in operating four UAS simultaneously and contributed to NASA meeting its stated goal of 24 UAS flying concurrently during the 1st flight window (0800-0900 hrs AST). UAF was able to get all four UAS in the air at the same time for flight window 1 (0800-0900 hrs) and flight window 3 (1000-1100 hrs). UAF was only able to launch two of the four UAS during flight window 2 (0900-1000 hrs). Difficulties during flight window 2 were attributed to challenges with multiple data links and implementation of the relatively complex system on a remote location local network infrastructure, with a temporary configuration, which had been set up specifically for this mission.

TCL2 demonstration outcomes: During the campaign, UAF successfully demonstrated the flight of 4-5 UAS simultaneously in close-proximity and various profiles, including airspace block altitude-stratified operations and EVLOS altitude-stratified operations. In addition, UAF demonstrated initial capabilities in several key technical areas: (1) successful parachute recovery of the S900 hexacopter; (2) investigation of rudimentary Detect And Avoid (DAA) between two UAS; (3) successful automated landing using laser altimeter using the S1000 octocopter; (4) initial investigation of Real-Time Kinetic (RTK) GPS; and (5) numerous improvements in the design and deployment of the computer-communications architecture supporting NASA's internet connectivity requirements.

Several important technical capabilities underpinning the ability to conduct BVLOS flights were developed or furthered, including incorporation of more capable navigation systems, long-range communications, surveillance systems, and geofence technologies. Details of these are provided below. Unfortunately, the short program timeline and limited flight time did not allow all capabilities to be fully realized within the flight campaign itself, but postured the team for future work the UTM program and related efforts within the Initial Pilot Program (IPP).

- Navigation. The laser altimeter system on the S1000 octocopter has proven highly successful, providing an unprecedented ability in accurately reporting altitude at high latitudes. The system 
also provided a new terrain-following capability valuable to scientific research and public service missions. In addition, the RTK GNSS system showed promise for supplying the increased accuracy needed for BVLOS missions involving landing/takeoff activities.

- UAS/GCS communications: The program enabled upgrades to UAF's purpose-built long-range UAS/GCS tracking antenna to increase its ruggedness and reliability. The antennas provide the capability of communications at significant distances $(20+\mathrm{km})$.

- UTM remote communications and video: The new video monitoring system performed admirably, providing the capability to remotely monitor launch/recovery operations. Its underlying communications infrastructure also dramatically extended the team's ability to operate using the UTM system via a portable wireless network in remote Alaska locations (which proved necessary for some flights conducted at PFRR).

- Geofence and emergency response mechanisms: UAF successfully demonstrated a parachute deployment system for the $\mathbf{S} 900$ hexacopter. The system was tested a total of three times over the course of the flight campaign, with each resulting in a successful chute deployment and UAS recovery. This capability provides valuable options when a UAS either exceeds the boundaries of a geofence due to extreme weather (wind) conditions, experiences a navigation malfunction, or must react immediately to an 'All Land' command supporting an emergency scenario. The parachute system supports manual commands and can automatically deploy at dangerous UAS attitudes or for a breach of a geofence.

In the area of operational methods and procedures, UAF tackled several important areas, which proved that the feasibility of various enabling processes was necessary for a safe BVLOS flight. UAF engaged in a series of venues, which then challenged the UTM system and our ability to utilize it. The primary focus for scenarios included: (1) altitude stratified operations; (2) Extended Visible-Line-Of-Sight (EVLOS) operations; and (3) altitude stratified EVLOS operations. Additionally, UAF implemented scenarios enabling: (4) dynamic replanning; (5) response to alerts from the UTM system; and (6) implementation of contingencies (e.g., sudden need for RTB).

- Multiple UAS: UAF conducted numerous mission sets involving up to five UAS flying simultaneously. This involved several scenarios, including combinations of altitude-stratified local operations and altitude-stratified EVLOS operations. The missions utilized several launch/recovery locations and demonstrated both fully centralized C2 of flight operations utilizing a single UTM operator for all UAS, as well as geographically distinct flight operations (separated by $35+$ miles) with two sets of UTM operators providing simultaneous centralized C2 over local UAS operations.

- UTM architecture: UAF employed a centralized approach to the UTM system using a single team member as the interface to the UTM system, with the UTM POC orchestrating the overall flight operations in close coordination with the flight director. As the missions included multiple simultaneous UAS (and crews/locations), the flight director was required to closely coordinate flight objectives and sequencing with the UTM POC in advance, so that flight boundaries and missions could be constructed, tested, deconflicted, and submitted prior to the flight.

- UTM response: While UAF did not begin with the concept of having the UTM system embedded with each flight crew, we did work with the NASA human factors team to find ways to gradually introduce the UTM system displays into the crews' equipment and incorporate this into their cross-check. We found that the crews were largely able to assimilate the UTM into their accepted procedures over time, first acknowledging audio warnings, then digesting the visual indications of flight boundaries and other UAS and aircraft in the area. Some crews became proactive in checking their flight boundaries with respect to other simultaneous flights prior to the scheduled take off.

TCL3 demonstration outcomes: UAF successfully conducted numerous flights involving 4-5 UAS simultaneously, to include tightly integrated altitude-stratified operations and dynamic airspace reallocation to support simulated emergency/high-priority operations. Technical accomplishments 
included: (1) numerous successful BVLOS automated landings using integrated laser altimeter/RTK systems (see video); (2) a terrain-following flight using the same as before; (3) demonstrated automated DAA using ADS-B technology; (3) UAF acquisition and successful first use of Echodyne MESA-SRR/DAA portable radar units for ground-based noncooperative DAA; and (4) successful integration of the parachute recovery system into the emergency avoidance scenario.

UAF also made significant progress in improving the use of the computer-communications equipment architecture to satisfy NASA's requirement for constant internet connectivity of operations. Significant improvements were made in the numbers and types of portable tactical communications antennas, high-capacity cellular modems, and local wireless communications equipment, and in securing access to UAF's computer-communications network for reliable operations.

Nearly all intended mission capabilities were demonstrated during the campaign, including incorporation of more capable navigation systems, communications, surveillance systems, and Sense And Avoid (SAA)/Detect And Avoid (DAA) technologies. Those that fell short due to time and resources continue to be addressed by UAF, especially as they are considered to be necessary capabilities for conducting BVLOS missions in the arctic. A synopsis of these is provided below.

- Communications: UAF's previous efforts focused on providing simple tactical communications between UAS and their associated Ground Control Stations (GCS). Under TCL3, the focus shifted to growing this into a fully networked system, supporting communications between the UAS, GCS, USS, as well as integrating sensors (e.g., radar) with the NASA UTM system. While elements of this system had already been demonstrated during TCL2 at PFRR, these operations had been conducted from a limited set of locations. Operations at UAF's main campus for TCL3 required a more flexible communications system supporting numerous operating locations and associated technical assets. This drove the design to be a more complex network of field-deployable, tactical communication links enabling communications amongst participant GCS and sensor assets from remote locations, as well as providing access to internet via a combination of WiFi and/or $4 \mathrm{G}$ cellular networks.

- Navigation: The TCL2 efforts demonstrated the basic capabilities of the laser altimeter system on UAF's S1000 octocopters to provide the terrain-following flight and assistance in automated landing. The S1000 also featured a Real Time Kinematic (RTK) GPS system, which was shown (accomplished after the TCL2 flight campaign) to provide greatly improved capability to support BVLOS landing operations. During the TCL3 campaign, UAF demonstrated the ability of this navigation system to successfully perform BVLOS landings/takeoffs at a variety of distances and flight conditions, including multi-leg BVLOS missions involving landing/takeoff operations. This was accomplished utilizing both a smaller F550 hexacopter and the heavier-duty S1000 platforms.

- SAA/DAA: UAF made significant progress in the area of SAA/DAA, improving the ability of flight crews to manually deconflict multiple vehicles using enhanced display tools and in furthering our ability to provide automatic deconfliction. Successes included: (1) improved visualization tools for flight crews on their GCS consoles, including both the standalone Simulyze USS Web Client and information injected into UAF's Mission Planner GCS consoles already used by flight crews; (2) demonstrated ability of the Pixhawk autopilot to utilize inputs from the Automatic Dependent Surveillance Broadcast (ADS-B) on board the UAS to generate automated avoidance commands against other intruding UAS or manned aircraft (accomplished post TCL3 flight campaign); (3) demonstrated ability of the Simulyze USS to ingest and process ground-based radar inputs (EchoDyne MESA-SSR) and display this traffic on the USS Web Client and the UAS Mission Planner GCS; and (4) demonstrated ability of the IRIS Automation Hedgehog Collision Avoidance Module (HCAM) and camera system to generate and provide audio/visual traffic warnings to the UAS operator. While UAF did not complete all 'reach-goals' for the effort (e.g., automated separation maneuvers commanded via radar inputs), we made progress and a plan to continue. 
Beyond these technical accomplishments, UAF engaged in a series of flight venues designed to further the capabilities of the UTM/USS system and our ability to utilize it. Focus for scenarios included: (1) BVLOS landing/takeoff operations (these were conducted as Enhanced VLOS operations, as we always had a safety spotter in place at the remote locations); (2) complex flight geometries in close proximity, including altitude stratified operations for CON1/2/4/5 scenarios; (3) field operations implementing flexible, deployable communications, and networking systems; (4) scenarios incorporating dynamic airspace replanning (e.g., emergency operations supporting various CON1/2/4/5 scenarios); and (5) scenarios designed to demonstrate the utility of increased visual/audio indications made available within the USS web client and UAS GCS displays.

- Environmental challenges: Most mission profiles planned for the TCL3 campaign were flown either as originally scheduled or with slight modifications-necessitated by weather conditions or to provide better flight value supporting NASA objectives. Not every mission set could be accomplished with the entire UTM system in concert as planned due to a combination of factors, including UAS/system capabilities, connectivity issues of the new UAF "wheel and spoke" communications architecture, late winter breakup, and bad weather (winds, rain, and snow).

- Multiple UAS: UAF performed numerous mission sets, which included flights by multiple simultaneous UAS (up to five, but generally $3-4$ ). These missions incorporated several airspace constructs, including combinations of altitude-stratified local and EVLOS operations. The missions utilized several launch/recovery locations and demonstrated both fully centralized C2 of flight operations utilizing a single UTM operator for all UAS, as well as two sets of USS operations providing simultaneous centralized $\mathrm{C} 2$ over respective UAS operations (CON4).

- UTM architecture: As with previous campaigns, UAF employed a centralized approach to the UTM system, generally using a single team member as interface to the UTM system. While UAF was not selected for operations involving interactions between competing USS systems, the team still successfully demonstrated this capability utilizing two separate instances of the Simulyze USS.

- UTM information to flight crews: While UAF primarily utilized a centralized UTM system for all flight crews, we did increase the amount of interaction between crews and the USS Web Client. Over time the team gradually introduced the UTM system displays into the crews' equipment and incorporated this into their mission planning and cross-check during mission execution. Not only did the flight crews demonstrate the ability to adopt this new tool, but Simulyze was able to inject much of the valuable airspace volume information and third-party UAS information (via ADS-B and the MESA-SSR radar) directly into the flight crew's organic Mission Planner GCS, keeping the information confined to a single display and in a more familiar (and safer) format.

\section{Discussion}

TCL1 lessons learned: timeline and complexity. With the complex set of NASA/UAF hardware and software components and interfaces, the overall UTM system proved to have a somewhat steep learning curve. A number of challenges presented themselves as the team worked to establish initial connectivity, primarily dealing with computer network communications settings at a remote location new to the UAF team. In addition, there were also some challenges with learning nuances of the NASA software. Some of this difficulty would have been lessened with a longer timeline for integration. However, as with any new complex system, the software suite itself must undergo an evolution as it moves from the development phase into operations. It is expected that the user interface for the suite of these software products will undergo significant learning and modification as a result of the experiences of UAF and the other test site teams involved in TCL1.

TCL2 lessons learned/recommendations: One of NASA's primary purposes for conducting the effort was to gain experience in how UAS teams might learn and utilize the UTM system in an increasingly complex environment. As such, UAF put much emphasis on creating scenarios that would generate sufficient complexity to simulate the higher level of UAS traffic reflected in this phase of UTM operations involving simultaneous operations with multiple UAS, personnel, and flight profiles 
for each day of the campaign. By design, the more complex scenarios at times stressed the team's ability to operate several simultaneous, coordinated missions using different UAS assets. Adding to the complexity was the learning curve posed by both the prototype NASA UTM and USS client interface, which provided NASA with insights into challenges that might be faced by novice users of the fielded UTM system.

NASA was sensitive to developing the UTM system in a fashion that seeks to minimize impacts on the operational community. To this end, NASA embedded human factors personnel within the test site teams to evaluate the impacts firsthand. In support, UAF provided an open window into the operations planning/conduct cycle so that NASA might observe a team learning how to work within the new constraints imposed by the system, as well as discovering potential benefits. A summary of observations/lessons learned and recommendations for the future follows:

- UTM functionality: At the beginning of the campaign, personnel had little experience with either the UTM system or a USS client interface. As the campaign progressed, UAF demonstrated the ability to successfully learn and utilize the NASA UTM system through our USS provider (Simulyze). The team was able to develop new tools for the UTM/USS interface that make it more powerful and user friendly. A few examples included: (1) the collaborative state, which allows multiple UAS to launch/operate/recover in the same airspace; (2) the pause state, which allows UAS missions requiring multiple flights (typically limited by battery endurance) to retain the airspace versus releasing it between each flight (and risk losing it to another user); and (3) feedback on internal naming conventions and features of the tool.

- $\quad$ UTM operator workload: The centralized UTM approach adopted by UAF for this effort placed a higher workload on the UTM POC. This was amplified for missions involving simultaneous operations by several UAS. While this was expected during the training/learning phase for new UTM operators, it was still a factor at times when very experienced UTM POCs were at the helm. Individuals did show rapid adaption to the environment and tasks, but they were still challenged at times with the workload associated with more than a few UAS. As expected, workload capacity and efficiency increased for everyone once the team exercised together a few times.

- UAS crew concept/workload: All communications were accomplished through the flight director to the central UTM POC. This approach was adopted because the prototype UTM was seen as an added layer of networking, which required specialized training to navigate, and could further encumber the UAS flight crews, possibly creating an unsafe operating environment. However, during the TCL2 flight campaign, guided by suggestions from the NASA human factors team, the team did begin to experiment with integrating the UTM functionality into the crew stations. A second laptop at each UAS ground station allowed crews to monitor audio warnings regarding their own or nearby UAS. Eventually, many of the teams began to check the visual display as conditions were permitted to get an increased sense of situational awareness. By the end of the campaign, crews began to proactively examine the potential interactions between their and other UAS flight boundaries prior to the mission.

TCL3 lessons learned/recommendations: For TCL3, UAF put forth an aggressive set of scenarios involving the new technologies of radar, optical camera, and ADS-B-based SAA/DAA. The campaign provided on opportunity for UAF and its partners to gain valuable experience regarding the development of advanced technical capabilities and USS features and provided important insights.

- $\quad$ Pace of the rapid development program: The overall pace of the UTM development program was challenging at times due to the rapid changes being made to the prototype UTM/USS software at this stage in the program. This was evidenced by a late lockdown of the developmental USS interface and required functions that sometimes slowed flight test efforts. In addition, late delineation of the Data Management Plan (DMP) requirements and formats had a negative impact on manpower and flight activities. DMP requirements for the early system were extensive, requiring much analysis of systems and training of both engineering and flight crew personnel. 
- UTM/USS communications (tactical communications): While overall beneficial to the test campaign, UAF's move of the flight operations from PFRR to the UAF campus area did come with new challenges. The UTM/USS communications were stressed by persistent issues with connections to the internet accessed via a 4G LTE and UAF wireless network. These issues further complicated the establishment of reliable communications supporting the UTM/USS system.

- UTM/USS communications (networking): The prototype system was complex, requiring an exacting sequence of events to be performed in a specific order to establish the communications links among UAS, USS, and UTM. This process was further complicated for flights involving additional assets such as the ground radar. The complexity of the procedure required $1-1.5 \mathrm{~h}$ to set the system up before each day of flight. In addition, the data link was somewhat temperamental with respect to data timing and signal levels, often requiring the system to be reset and/or for missions to be reflown. The complexity of these issues required UAF to dedicate a full-time engineer solely to the task of UTM/USS communications.

Beyond the learning opportunities and problem-solving techniques mentioned above, UAF benefitted significantly from participation in the UTM TCL3 campaign in several other areas.

- USS integration into GCS: NASA demonstrated much concern for developing the UTM system in a fashion that sought to minimize impacts on the operational community. In support of this, in TCL3 UAF attempted to integrate the UTM/USS functions more directly into the flight crews' operations by providing USS Web Client machines either colocated or in close proximity to flight crews. UAF/Simulyze was successful in integrating much of this information directly into the Mission Planner GCS. This integration proved especially valuable in providing the flight crews with situational awareness of their UAS in relation to airspace volumes and nearby UAS/aircraft.

- Automated ADS-B SAA/DAA; UAF successfully demonstrated the initial capability of the automated SAA/DAA function utilizing the Pixhawk/ADS-B interface. While this did take a fair amount of effort to troubleshoot and had to be set aside temporarily during the UTM data collection runs, the system was subsequently shown to operate reliably for passive and active lateral separation of aircraft and shows great promise for future efforts, both within the UTM evolutionary program and UAF mission operations. This function increased the likelihood for further automated ABDAA and GBDAA capabilities, based upon our MESA-SSR/DAA radars and IRIS Automation HCAM assets. Note: ADS-B use has since been discontinued by the FAA with the capabilities being replaced by various systems such as Remote Identification (RID). UAF's work did not include any analysis on the link reliability of the ADS-B signal.

Related FAA/NASA UTM programs: At the conclusion of TCL3, NASA continued to develop technical tools and investigations of procedural techniques into UTM TCL4 with a focus on autonomous UAS operating in a high-density and highly interactive environment. During this time, the FAA developed the UTM pilot program focusing on solidifying the previous gains into a set of more operational tools and procedures.

UAF's future efforts: Due to its location and inherent mission sets, UAF remains dedicated to further developing key UAS capabilities, which enables the BVLOS flight in Alaska. These areas are vital for conducting meaningful and practical missions supporting arctic research, critical infrastructure, and public service missions.

- RTK GPS: Further tests of the BVLOS system need to be completed to better understand the capabilities and limitations of the RTK GPS system at different speeds and distances from the ground station, as well as the ability to handoff to secondary systems providing RTK GPS from remote locations. These capabilities are necessary for longer-distance BVLOS missions into remote locations of the state for payload delivery/retrieval and conducting of other recurring mission sets.

- UAS failsafe measures: Further development is necessary for UAS safety systems designed to prevent or mitigate damage or injury due to UAS failure in flight, and to provide for enhanced 
airspace clearing methods in the case of high-priority missions. Example systems could include visual/auditory warnings to enhance our existing parachute recovery system or inflatable bladders designed to minimize the effects of an impact with personnel or objects.

- GBDAA: Testing is needed on ADS-B or similar communication signal protocols injected into the mission planner GCS laptop as a means of generating automated GBDAA commands. One application is to demonstrate the use of the Echodyne MESA-SSR ground radar as means for generating automated GBDAA commands. The next steps would be to demonstrate the ability to use this equivalent ADS-B format message to command UAS separation via GCS/MAVLink, and finally to accomplish this function directly by the UAS.

- $\quad$ ABDAA: The Echodyne MESA-DAA radar needs to be integrated with UAS such as the Tarot X6 hexacopter as a flight test bed. This will require the integration of new IMU sensors to accurately measure offsets of the radar with respect to the UAS, and of the UAS with respect to the coordinate system. Demonstration of the ability of the MESA-DAA airborne radar to provide automated ABDAA commands is also required.

\section{Conclusions}

The UTM program has proven quite valuable in laying a foundation for integrating UAS into the NAS. Notable progress has been made on several fronts.

UTM framework and procedures: Through much hard work on the part of NASA and the FAA, the UTM architecture is becoming well-established and has been communicated widely within the UAS and manned aviation communities, both within the US and internationally. This framework has been used as an important model for the systems being investigated by the International Civil Aviation Organization and under development with other regions and countries. While a definitive set of FAA-approved procedures has yet to be released, the extensive work performed under the NASA and FAA UTM efforts has provided much of the required ground work in identifying practical, workable, and safe practices, which will form the governing policies, regulations, and practices.

UAS vehicle/sensor technologies: The UTM program has been pivotal in identifying key technologies needed to support the demanding levels of safety with respect to UAS/UTM communications, navigation, and vehicle autonomy required for high-density UAS flight within the NAS. Significant achievements have been made by the UAS test sites and their partners in several areas: (1) UAS position sensing and reporting; (2) ground-based sensors, such as radar, for tracking and GBDAA; (3) airborne sensors, such as vision-based, acoustic/ultrasonic, and lidar/radar for larger UAS; (4) automated landing/takeoff and UAS battery recharging; (5) seamless transition of UAS flight between outdoor/indoor (GNSS-denied) environments; (6) UAS vehicle health monitoring and reporting; and (7) UAS failsafe capabilities addressing lost navigation/communication (NAV/comm), lost power, and vehicle recovery after emergency landing or a crash. Much remains to be done before these systems are truly ready for the general consumer, but all issues appear to be solvable, given adequate attention and resources.

UTM communications: One overarching challenge for the UTM system remains that of providing continuous, uninterrupted communications between the UAS and the UTM FIMS via a set of USS providers. These communications may be via cellular networks, WiFi/Bluetooth, or satellite systems. Availability of cellular systems varies considerably across the nation, with ample coverage found in most urban population centers and many rural communities, yet with sparse or no coverage found in more remote locations like most of Alaska. WiFi/Bluetooth and similar networks may prove suitable when operating around major metropolitan centers, business complexes, or with groups of UAS and ground entities forming ad hoc networks. Satellite systems can provide a failsafe communications channel when no other options are available but are of much lower bandwidths.

All of these communications systems are generally bandwidth-limited with respect to sensor/payload data streams. WiFi may often prove suitable for transmitting medium or low-resolution video, but this depends upon the distance of the UAS to the GCS, power levels of transmitted signals, 
antenna design and placement, receiver capability, modulation scheme, and number of users sharing the link. Cellular signals often can support comparable data rates, but is also dependent on similar factors. While streaming a video may be supported close to cellular repeaters, this capability drops off dramatically further away from the GCS and may only support an occasional, lower resolution picture. Satellite communications for UAS are generally incapable of supporting anything but periodic positional reports/commands, and this may be at intervals of 2-10 min or more. Any of these systems, when present, may support basic UTM position-reporting/command functionality, but may not be sufficient for communications demanding immediate access or higher data bandwidths to support powerful sensors like the camera or radar data for SAA/DAA.

The UTM program led by NASA and the FAA has laid a solid foundation that will ultimately lead to the safe integration of UAS into the US NAS. The FAA has been in an unenviable position in attempting to strike a balance between the public outcry for opportunity and national interest in securing our place in this new market, while upholding their solemn responsibility to provide the safety demanded and deserved by our manned aviation community. While UAS integration into the NAS is not fully complete, smart progress often comes slowly.

\section{Abbreviation}

\section{Acronyms}

ABDAA

ACUASI

ADS-B

AGL

AST

BVLOS

C3

CEP

CNS

DAA

DMP

EVLOS

FAA

FIMS

FPMS

FPS

GBDAA

GCS

GDOP

GNSS

GPS

HCAM

HDOP

$\mathrm{HP}$

IMU

LOS

LTE

NAS

NASA

PFRR

POC

PPS

\section{Airborne-Based DAA}

Alaska Center for Unmanned Aircraft Systems Integration

Automatic Dependent Surveillance-Broadcast

Above Ground Level

Alaska Standard Time

Beyond Visual Line-Of-Sight

Command, Control, and Communication

Circular Error Probable

Communication, Navigation, and Surveillance

Detect And Avoid

Data Management Plan

Extended Visual Line-Of-Sight

Federal Aviation Administration

Flight Information Management System

Flight Path Monitoring Service

Flight Planning Service

Ground-Based DAA

Ground Control Station

Geometric Dilution of Precision

Global Navigation Satellite System

Global Positioning System

Hedgehog Collision Avoidance Module (IRIS)

Horizontal Dilution of Precision

Home Point

Inertial Measurement Unit

Line-Of-Sight

Long Term Evolution (4G)

National Airspace System

National Aeronautics and Space Administration

Poker Flat Research Range (UAF)

Point of Contact 


$\begin{array}{ll}\text { RTB/RTL } & \text { Return To Base/Return To Launch } \\ \text { RTK } & \text { Real-Time Kinematic } \\ \text { RTT } & \text { Research Transition Team } \\ \text { SAA } & \text { Sense-And-Avoid } \\ \text { SAS } & \text { Separation Assurance Service } \\ \text { TAPS } & \text { Trans-Alaska Pipeline System } \\ \text { TCL } & \text { Technical Capability Level } \\ \text { TSO } & \text { Test Site Operator } \\ \text { UAF } & \text { University of Alaska Fairbanks } \\ \text { UAS } & \text { Unmanned Aircraft Systems } \\ \text { USS } & \text { UAS Service Provider } \\ \text { UTM } & \text { UAS Traffic Management } \\ \text { VDOP } & \text { Vertical Dilution of Precision } \\ \text { WP } & \text { Way Point }\end{array}$

Author Contributions: Conceptualization, M.H., P.W.; methodology, M.H.; formal analysis, M.H., J.G.; investigation, M.H., P.W. and R.B.; resources, M.H. and C.C.; writing-original draft preparation, M.H., R.B., C.C., J.G. and P.W.; writing-review and editing, C.C., J.G., P.W. and R.B.; visualization, M.H. and R.B.; supervision, M.H. and C.C.; project administration, M.H. and C.C.; funding acquisition, M.H. and C.C. All authors have read and agreed to the published version of the manuscript.

Funding: This research was funded by NASA, grant number NND15SA81B.

Acknowledgments: The authors would like to thank NASA AMES for their funding of these grants and for their kind support of the University of Alaska Fairbanks in their efforts to achieve BVLOS flight capabilities. Additionally, the authors extend their appreciation to Simulyze USS, Echodyne radar, IRIS Automation, and to all of our other partners for their extensive support of UAF's participation in the UTM campaign.

Conflicts of Interest: The authors declare no conflict of interest. The funders had no role in the collection, analyses, or interpretation of data; in the writing of the manuscript, or in the decision to publish the results.

\section{Appendix A Excerpts from NASA TCL Statements of Work}

\section{TCL1.}

The TSO (Test Site Operator) shall use NASA's UTM construct and/or initial system and procedures to demonstrate safe multi-vehicle operations in the vicinity. The UTM system will contain and display all constraints (real and simulated), which will include geofenced areas, severe wind/weather, ongoing operations, etc. The users shall connect to UTM, provide an operational plan, connect trajectories, and track the progress of trajectories. NASA will provide the UTM interface control document. The test shall conduct an initial demonstration test (shakedown test) that includes at least two vehicles operating for 30 minutes.

\section{TCL2.}

The TSO shall use NASA's UTM construct and procedures to demonstrate safe multi-vehicle operations sharing the same airspace. This airspace may be beyond visual line of sight of the operator and the operations may be altitude stratified. Airspace management procedures may include dynamic replanning, contingency implementation, and support of public safety vehicles, amongst others. These procedures will be detailed and provided by NASA, potentially finalized through collaboration with the TSO.

In addition to the procedures outlined above NASA requests each test site to focus on one or more of the following areas:

- UAS service supplier technologies and procedures,

- Geofencing technologies/conformance monitoring,

- Ground-based surveillance/sense and avoid,

- Airborne sense and avoid,

- Communication, navigation, and surveillance,

- Human factors related to UTM data creation and display. 
Flight testing will exercise the following functionality, which the TSO will ensure that tools and processes are in place to efficiently execute. Note that this list is non-exhaustive and may expand based on discussions between NASA and the TSO:

- Altitude stratified operations,

- BVLOS operations,

- Altitude stratified BVLOS operations,

- Dynamic (en route) replanning,

- Response to alerts from the UTM system,

- Implementation of contingencies (e.g., sudden need for RTB).

TCL3.

The following test descriptions are provided to allow the TSO to effectively determine its ability to execute this task order and properly estimate resources. A TSO may select the subset of these tests that fit the TSO's resources and technical capabilities.

The following tests are grouped into four areas:

1. CNS: Communication, Navigation, and Surveillance,

2. SAA: Sense and Avoid,

3. DAT: Data and Information Exchange,

4. CON: Concepts.

Specific objectives for these were identified in detail within the SoW and accompanying Concept of Operations (ConOps) document.

- CNS1, Maintaining Control of UAS with Redundant C2,

- CNS2, Remaining Within Flight Geography Using GNSS Navigation,

- CNS3, RF Interference Baseline Monitoring,

- $\quad$ SAA1, Conflict Mitigation Cooperative Technology for UAS-UAS Interaction,

- SAA2, Conflict Mitigation Cooperative Technology for UAS-Manned Interaction,

- SAA3, Conflict Mitigation Non-Cooperative Technology for UAS-Manned Interaction,

- SAA4, Conflict Mitigation Non-Cooperative Technology for UAS-UAS Interaction,

- SAA5, System Level Assessment and Off-Nominal Conditions,

- SAA6, Remote Identification and Interoperability with Automobiles Using Cooperative Technology,

- DAT1, End-to-End UREP,

- DAT2, FIMS Failover,

- DAT3, USS Failover,

- DAT4, UAS ID,

- DAT5, USS-USS Negotiation,

- DAT6, Weather Service,

- CON1, BVLOS Landing,

- CON2, Contingency Initiation,

- CON3, Public Portal,

- CON4, Multiple Operations for Sustained Period,

- CON5, FIMS/USS Interaction to Mitigate Undesired UAS Behavior.

\section{References}

1. Nath, T. How Drones Are Changing the Business World. Available online: https://www.investopedia.com/ articles/investing/010615/how-drones-are-changing-business-world.asp (accessed on 4 July 2020).

2. M \& R Forwarding (HK) Limited. Unmanned Aerial Vehicle (UAV) Market to 2025-Global Analysis and Forecasts by Component by Type and Application. Available online: https://www.researchandmarkets.com/ reports/4460849/unmanned-aerial-vehicle-uav-market-to-2025 (accessed on 4 July 2020). 
3. Global UAV Market-Research Report Analysis By Forecast 2028. Available online: https://www. marketresearchfuture.com/reports/uav-market-1131 (accessed on 4 July 2020).

4. FAA Investigation of UAS Accidents and Incidents. 26 September 2017. Available online: https://sites. nationalacademies.org/cs/groups/depssite/documents/webpage/deps_183066.pdf (accessed on 4 July 2020).

5. Facts and Figures. Available online: http://www.droneinnovation.org/facts-and-figures.html (accessed on 4 July 2020).

6. Unmanned Aerial Vehicle (UAV) Market Worth $\$ 83.6$ Billion by 2027-Exclusive Report by Meticulous Research ${ }^{\circledR}$. AI Ind. News 2020. Available online: https://www.benzinga.com/pressreleases/20/03/g15577906/ unmanned-aerial-vehicle-uav-market-worth-83-6-billion-by-2027-exclusive-report-by-meticulous-resea (accessed on 12 September 2020).

7. Nichols, R.K.; Ryan, J.J.C.H.; Mumm, H.C.; Lonstein, W.D.; Carter, C.; Hood, J.P. Chapter 1: A View of the UAS Market. In Unmanned Aircraft Systems in the Cyber Domain; New Prairie Press: Manhattan, Kansas, 2019.

8. AUVSI. The Economic Impact of Unmanned Aircraft Systems Integration in the United States. 2013. Available online: https://robohub.org/_uploads/AUVSI_New_Economic_Report_2013_Full.pdf (accessed on 12 September 2020).

9. Ghasri, M.; Maghrebi, M. Factors Affecting Unmanned Aerial Vehicles' Safety: A Post-Occurrence Exploratory Data Analysis of Drones' Accidents and Incidents in Australia; Available online: https:/trid.trb.org/view/ 1693161 (accessed on 4 July 2020).

10. Nichols, R.K.; Ryan, J.J.C.H.; Mumm, H.C.; Lonstein, W.D.; Carter, C.; Hood, J.P. Chapter 2: UAS Law-Legislation, Regulation, and Adjudication. In Unmanned Aircraft Systems in the Cyber Domain; New Prairie Press: Manhattan, Kansas, 2019.

11. FAA Predicts the Commercial Drone Market Will Triple by 2023. Available online: https://www.nextgov. com/emerging-tech/2019/05/faa-predicts-commercial-drone-market-will-triple-2023/156743/ (accessed on 4 July 2020).

12. UAS by the Numbers. Available online: https://www.faa.gov/uas/resources/by_the_numbers/ (accessed on 4 July 2020).

13. Chauhan, B.B. Unmanned Aerial System Integration into the National Airspace System and Airports: Risk Mitigation Using Content Analysis Methodology. Ph.D. Thesis, Florida Institute of Technology, Melbourne, FL, USA, 2019.

14. UAS Test Site Program. Available online: https:/www.faa.gov/uas/programs_partnerships/test_sites/ (accessed on 23 July 2020).

15. Johnson, M.; Jung, J.; Rios, J.; Mercer, J.; Homola, J.; Prevot, T.; Mulfinger, D.; Kopardekar, P. Flight Test Evaluation of UTM Concept for Multiple Beyond-Visual-Line-of-Sight Operations; 12th USA/Europe ATM R\&D Seminar: Seattle, WA, USA, June 2017.

16. Unmanned Aircraft System Traffic Management (UTM). Available online: https://www.faa.gov/uas/research development/traffic_management/ (accessed on 23 July 2020).

17. UTM Pilot Program (UPP). Available online: https://www.faa.gov/uas/research_development/traffic management/utm_pilot_program/ (accessed on 23 July 2020).

18. About Alaska Test Site (PPUTRC) | ACUASI. Available online: https://acuasi.alaska.edu/pputrc (accessed on 23 July 2020).

19. U.S. Department of Transportation, Federal Aviation Administration. Concept of Operations V2.0 Unmanned Aircraft Systems (UAS) Traffic Management (UTM). 2020. Available online: https://utm.arc.nasa.gov/docs/ 2020-03-FAA-NextGen-UTM_ConOps_v2.pdf (accessed on 12 September 2020).

20. U.S. Government Accountability Office. Unmanned Aircraft Systems, FAA Could Better Leverage Test Site Program to Advance Drone Integration, GAO-20-97.2020. Available online: https://www.gao.gov/assets/710/ 703726.pdf (accessed on 12 September 2020).

21. NASA Tests a Drone Traffic Control System | Digital Trends. Available online: https://www.digitaltrends. com/cool-tech/nasa-testing-drone-traffic-control-system/ (accessed on 23 July 2020).

22. Publications-Dr Michael Hatfield. Available online: https://sites.google.com/a/alaska.edu/dr-michaelhatfield/publications (accessed on 23 July 2020). 
23. Culler, J. Digital Press Kit-Unmanned Aircraft Systems Traffic Management Tests. Available online: http: //www.nasa.gov/presskit/ames/utm-tcl2/reno (accessed on 23 July 2020).

24. A1.Pdf. 2017. Available online: http://www.newsminer.com/a1-pdf/pdf_0ad39f34-4b60-11e7-a26e8316a6e59169.html (accessed on 23 July 2020).

(C) 2020 by the authors. Licensee MDPI, Basel, Switzerland. This article is an open access article distributed under the terms and conditions of the Creative Commons Attribution (CC BY) license (http://creativecommons.org/licenses/by/4.0/). 